\title{
USE OF LARGE OPEN SPACES RESULTED FROM PUBLIC-PRIVATE NEGOTIATIONS IN OSAKA, JAPAN
}

\section{Rogério Akamine}

Arquiteto e mestre em arquitetura e urbanismo (FAUUSP), doutorando pela Graduate School of Engineering, Department of Architectural Engineering, Osaka University.

\section{Kunio Funahashi}

Professor titular da Graduate School of Engineering, Department of Architectural Engineering, Osaka University; Dr., Eng.

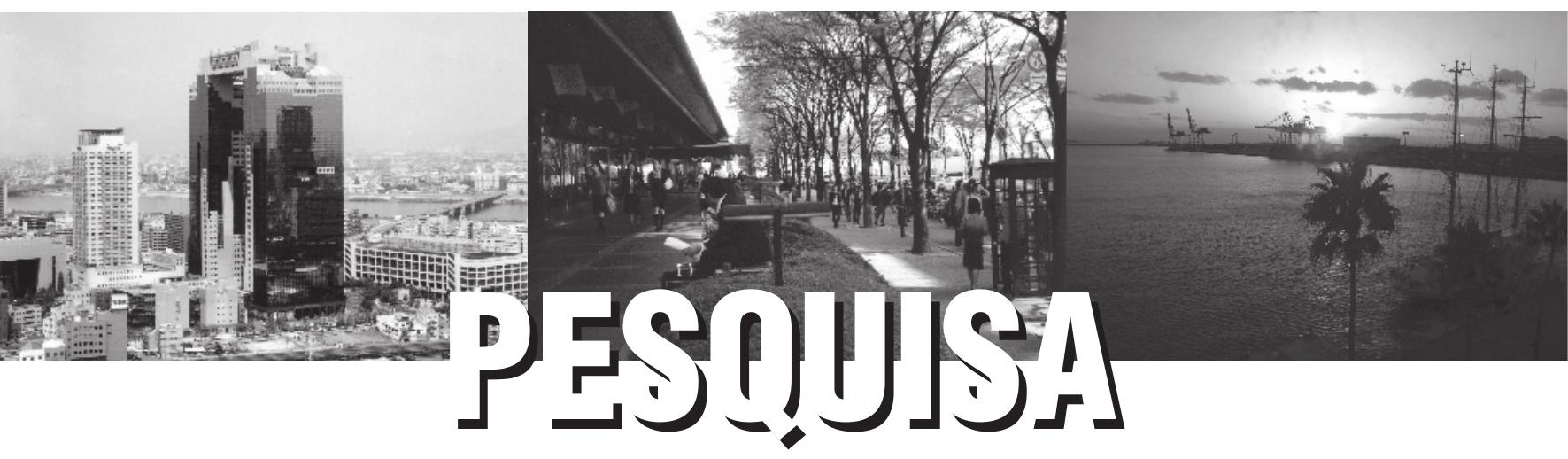




\title{
RESUMO
}

Este estudo tem foco sobre como e por quem os espaços livres de edifição resultantes de negociações público-privadas estão sendo usados, e como suas configurações espaciais podem ser avaliadas. Observações sistemáticas foram feitas em cinco lugares na cidade de Osaka, Japão. Os dados coletados foram organizados para expressar o perfil dos usuários no que diz respeito à população, sexo, idade, grupo e atividades. Registros de usuários de acordo com a hora do dia e diferenças entre um dia da semana e um dia de fim de semana confirmaram concretamente o ritmo ou o ciclo semanal de uso intuitivamente peculiar a distritos de negócios. Além disso, o mapeamento de usuários revelou os lugares preferidos para se estar de cada caso estudado, e então, estes puderam ser analisados em relação às entradas de edifícios e às vistas mais interessantes.

Palavras-chave: Renovação urbana, negociações público-privadas, Osaka, análise de desenho, estudos de comportamento-ambiente.

\begin{abstract}
This study focuses on how and by whom open spaces resulted from public-private negotiations are being used, and how their space configuration can be evaluated. Systematic observations were carried out at five places in Osaka city, Japan. The collected data was organized to express the profile of users with regard to population, gender, age, groups and activities. Registration of users according to time of a day and differences between a weekday and a weekend day concretely confirmed the rhythm or the weekly cycle of use, which are intuitively peculiar of business districts. Furthermore, the mapping of users revealed the preferred places to stay of each case of study, and then those places could be analysed in relation to building entrances and the most interesting views.
\end{abstract}

Key words: Urban renovation, public-private negotiations, Osaka, analysis on space design, environment-behavior studies. 


\section{USE OF LARGE OPEN SPACES RESULTED FROM PUBLIC-PRIVATE NEGOTIATIONS IN OSAKA, JAPAN}

\section{Introduction}

Since the 1960's when the Incentive Zoning was established in New York city, local governments around the world have adopted the model of relaxation for urban restrictions to promote public facilities. The basic idea is that builders can construct more floor area than defined by zoning if they create public space in the private site. Then, such a kind of space is called privately owned public space ${ }^{1}$, or pops for the purpose of this study.

In urban renovations, decadent industrial or port areas have enormous potential to incorporate the benefits of public-private partnership through the mechanism that produces pops. On the one hand, dirty environment, related to industrial activities with coal, factory smoke and water pollution, has been removed from cities, as described by Kuroda (1991). On the other hand, wide sites are now available to new real estate enterprises. Due to urban expansions, many of those sites have become strategically situated inside transportation system and, not rare, easily accessible from central areas. Skyscrapers and huge buildings for offices, shopping malls, hotels and sometimes for residences are commonly what have taken the place of decadent activities in those sites. For city inhabitants, each new enterprise represents a valuable opportunity to gain public space.

Fundamentally, the main difference between pops and usual open spaces is a combination of higher frequency in maintenance, stronger feeling of security and more restrictions in use ${ }^{2}$. This new type of open space produced in occasion of urban renovations is very important to be investigated, because of the unfamiliar results in relation to effective public use of spaces in private enterprises. In a methodical way, the present study focuses on the analysis of

(1) KAYDEN (2000, p. 7-19) historically describes the context where the regulations for privately owned public space were originated. It is intrinsically related to the evolution of zoning regulations in New York city and the mechanisms to get better space conditions to the public in a densely populated area. Results are space configurations, such as plazas, urban plazas, sidewalk widening, atriums, and others.

(2) In our doctoral dissertation (AKAMINE, 2003, p. 69-71), the results based on interviews show that users recognized that the studied pops, in contrast to usual open spaces, have higher frequency of maintenance, more feeling of security due to the presence of guards and other people, and fewer possibilities for activities, once just the calm ones were allowed, such as sitting and walking.

The relations benefits and deprivation of use in pops should achieve a good balance by means of the negotiations between the local government and the private enterpreneurs. The results of soul negotiations are certainly preceived by users after the opening of spaces. 
pops as a first approach to use aspects by means of systematic observations. The purpose is to make clear the relation space configuration and use in pops, and then to establish parameters for future studies that include comparisons with other cases alike and usual open spaces.

The concept of pops for japanese cities is similarly incorporated in the Kokaikuchi, which is generated by the Sogo-Sekkei-Seido (Comprehensive Design System ${ }^{3}$, based on the Incentive Zoning model) and it is supported by the KenchikuKijun-Hou (Building Standards Act). Osaka city has representative experiences in urban renovations with creation of pops, from singular lots to large portions defined in planning projects, the Saikaihatsu-Chiku-Keikaku (District Planning to Promote Proper Redevelopment ${ }^{4}$ ).

Although the present study was carried out in Japan, it is worth mentioning that in São Paulo, Brazil, there are experiences that resemble pops, for example the Cetenco Plaza's open space at av. Paulista, or the Centro Empresarial Itaú's open space just close to the Conceição underground station, both private lands with public access permitted. These brazilian examples are mentioned here to express the relevance of the present analysis and to be considered as cases for subsequent studies 5 .

Evaluation of what is produced as privately owned public space has been already done, such as the recognized study on plazas by William $\mathrm{H}$. Whyte. Based mainly on interviews and observation of users in New York city, Whyte (1979) contributed with many suggestions to improve law regulations for urban plazas $^{6}$ in the 1975 Zoning Revision.

(3) According to Osaka city government $(1997$, p. 42) in the Planning of Osaka City, Comprehensive Design System is "an authorization system that relaxes limits on the ratio of building volume to lot area and building height. Such authorization is given to large structures, with open space secured for public use, thus contributing to the environmental improvement of urbanized areas".

(4) Osaka city government (1997, p. 35), italicized term by the authors) defines in the Planning of Osaka City: "the purpose of District Planning for Promoting Proper Redevelopment is to encourage well-planned redevelopment of these sites (of former factories and large vacant lots) by framing development plans for the required public facilities and applying restrictions to buildings."

(5) ALY (2000) wrote about the role of buildings that generate open spaces for public use, such as the Centro Empresarial Itaú Conceição, in which the private company (Itauplan) exchanged open space for some zoning concessions made by the EMURB (section of the local government) in the early 1980's. Another mentioned example was the Cetenco Plaza's open space that also has public access in private lands. For a consistent statement about the use aspects based on comparisons between the japanese cases presented here and the brazilian ones, it would be necessary to adopt the same methodology of research, such as the application of the same research techniques. The process would demand significant effort and time, but it could be opportune for new investigations.

(6) The legal term plaza changed to urban plaza after 1975 with implementation of simple conditions to be answered in order to guarantee a successful use. Loukaitou-Sideris \& Baneriee (1998, p.103) described in essence those design guidelines for urban plazas: "define the minimum size of plaza spaces, the maximum permissible height of plaza, the minimum number of threes, and the amount of seating." 
In Japan, recent studies on open spaces are generally supported by data collected through questionnaires and interviews, for example the works of Hirai \& Nishimura (2001) or Watanabe et al (2001). They mainly get opinions and beliefs of users about open space, or its meaning and convenience in use, and then express a framework of studied cases.

Observation as method for evaluation of open spaces and their use goes into diverse ways. For example, observation that identifies spatial shapes and makes their classification possible in groups by similarity, as the study on configurations of Horiguchi et al (2001). An extreme case was the intensive way of Hanazato et al (1997), who took 24 turns a day for mapping registration of human behavior in a limited area ${ }^{7}$. Sommer \& Sommer (1997, p. 5) wrote that observation reveals the way users really act at open spaces. It is more detailed than verbal methods ${ }^{8}$, such as interviews or questionnaires, when respondents are less precise than just describing their behavior in their own words.

In some cases, the projects of urban renovation resulted from public-private partnership with very wide areas of open spaces, which are equivalent to urban squares or parks. Then, a constant evaluation of such a kind of negotiation becomes more and more necessary as its application has become usual. The methodical approach to five big projects at once brings the originality to the present study.

\section{Objectives and Methods}

The objective of this study is a reflection on how an open space produced as pops may be methodologically evaluated if configuration and use are considered, especially the large ones, in order to check the real benefits for the public. Although, the conditions vary from case to case, for example the situation in the city, area, functions of buildings, shape of open space and existent panoramic views, some regularities of use that relate to space design are expected to be detected. Then, the results can improve the process of negotiation and elaboration of design concepts through a better understanding of how those open spaces are used.

(7) According to the objectives of each research, disposition of time and resources, the researcher has to define conditions of observation, such as number of turns a day, on days of week, according to seasons or whether conditions, number of cases, etc.

(8) Questionnaires and interviews were applied techniques at the neighborhoods of three cases to understand the relation between open spaces and use of inhabitants. Nevertheless, observation revealed to be comparatively more precise to describe real uses at open space (the place centered viewpoint). 
Five cases in Osaka city, resulted from the conditions defined in the Comprehensive Design System, were chosen because of the uniqueness in their configurations, and because of the fact that they have a constant presence of users. They are Shin-Umeda City (SUC), Osaka Business Park (OBP), Osaka Garden City and close surroundings (OGC area), Osaka Amenity Park (OAP) and AsiaPacific Trade Center (ATC). As method from the Environmental Psychology, or broader, from the Environment-behavior studies" ${ }^{9}$, systematic observation and behavioral mapping ${ }^{10}$ were carried out on a weekday (Tuesday) and a weekend day (Saturday or Sunday) (Table 1), five times each day and following the same route each turn. These data allow a description of the registered population (gender, apparent age, number of integrants by group, density, business related people and activities), and also comparisons between places and time. Besides this, the collected information reveals in behavioral mapping the preferred places which may be analysed in relation to the panoramic views and entrances of buildings.

\begin{tabular}{|c|c|c|}
\hline \multicolumn{3}{|c|}{ Tabela 1: Systematic observation - date and weather } \\
\hline Place & Date & $\begin{array}{l}\text { Average temperature } \\
\text { and weather condition }\end{array}$ \\
\hline ATC & 2000 Apr. 25 Tuesday & $20^{\circ} \mathrm{C}$ Sunny \\
& 2000 Apr. 23 Sunday & $22^{\circ} \mathrm{C}$ sunny windy \\
\hline SUC & 2000 Apr. 18 Tuesday & $20^{\circ} \mathrm{C}$ Sunny windy \\
& 2000 Apr. 16 Sunday & $19{ }^{\circ} \mathrm{C}$ sunny - cloudy \\
\hline OGC area & 2000 Apr. 19 Tuesday & $24^{\circ} \mathrm{C}$ Sunny \\
& 2000 Apr. 19 Sunday & $26^{\circ} \mathrm{C}$ sunny \\
\hline OBP & 2000 Apr. 17 Tuesday & $23^{\circ} \mathrm{C}$ Sunny \\
& 2000 Apr. 13 Sunday & $26^{\circ} \mathrm{C}$ sunny \\
\hline OAP & 2000 Apr. 29 Tuesday & $28^{\circ} \mathrm{C}$ Sunny \\
& 2000 Apr. 2 Sunday & $28^{\circ} \mathrm{C}$ sunny \\
\hline
\end{tabular}

Source: Provided by the authors

(9) Environmental Psychology is a study field defined by VEITCH (1995, p. 4) as "behavioral science that investigates, with an eye toward enhancing, the interrelationships between the physical environment and human behavior". However, MOORE (1997, p. 1, italicized term by the authors) defined the field of study in wider extents: "The more general term 'environment and behavior' encompasses environmental psychology, behavioral and social geography, environmental sociology, human factors, social and behavioral factors in architecture, and urban social planning. The range of theories discussed in this chapter will pertain not only to those in environmental psychology but also to those in the broader environment, behavior, and design field."

(10) Sommer \& Sommer (1997, p. 60) present the utility of this method: "A special application of observational procedures, behavioral mapping is a technique for systematically recording people's locations and actions. A behavioral map is an actual chart of individual's locations in space. It is an empirical document that illustrates where and what behaviors actually occur, which may contrast with what was planned for the space." 


\section{Situation of the Cases and Counted People}

Osaka city is situated in a mouth of rivers, immediately adjacent to the Osaka bay (Figure 1). The center area is easily identified because of the canals and rivers around it. All chosen projects are around the central area of the Osaka city, but close to strong landmarks and references, such as the Osaka castle, the Osaka station and the Osaka bay. Three of the five study cases, the Osaka Garden City area (OGC area), the Osaka Amenity Park (OAP) and the AsiaPacific Trade Center (ATC) ${ }^{11}$ were defined by the planning of Osaka city as District Planning to Promote Proper Redevelopment.

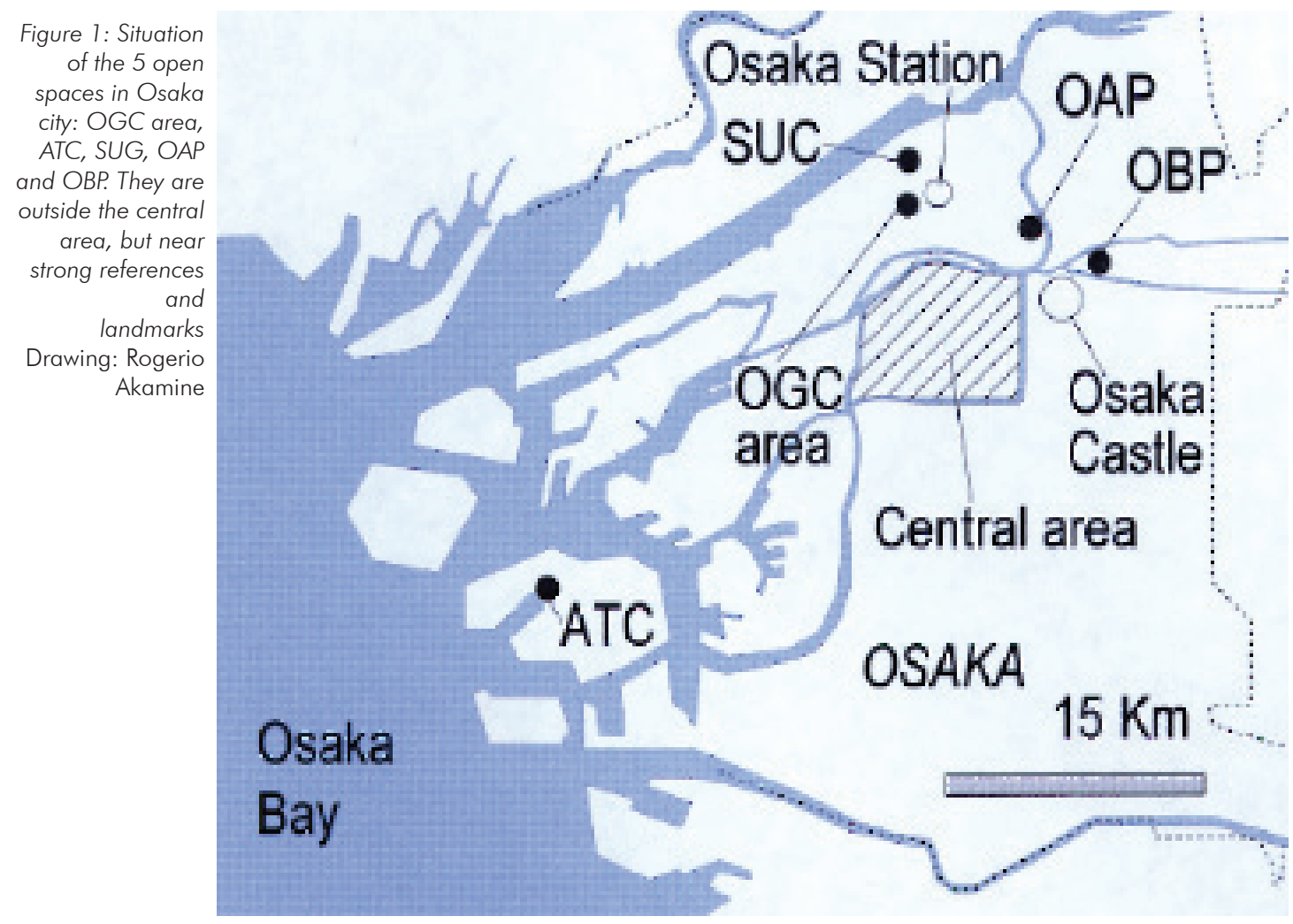

The following part is a short description of each case study, in which relevant aspects about functions of buildings, space configurations and connections, panoramic views and sitting places are presented (observation areas and routes are indicated on the related drawings: Figure 3.1 to 3.5).

(11) Nishi Umeda, Tenmabashi 1 - chome and Osaka Nanko: Cosmo Square are the names of the defined areas where OGC area, OAP, ATC are situated. 

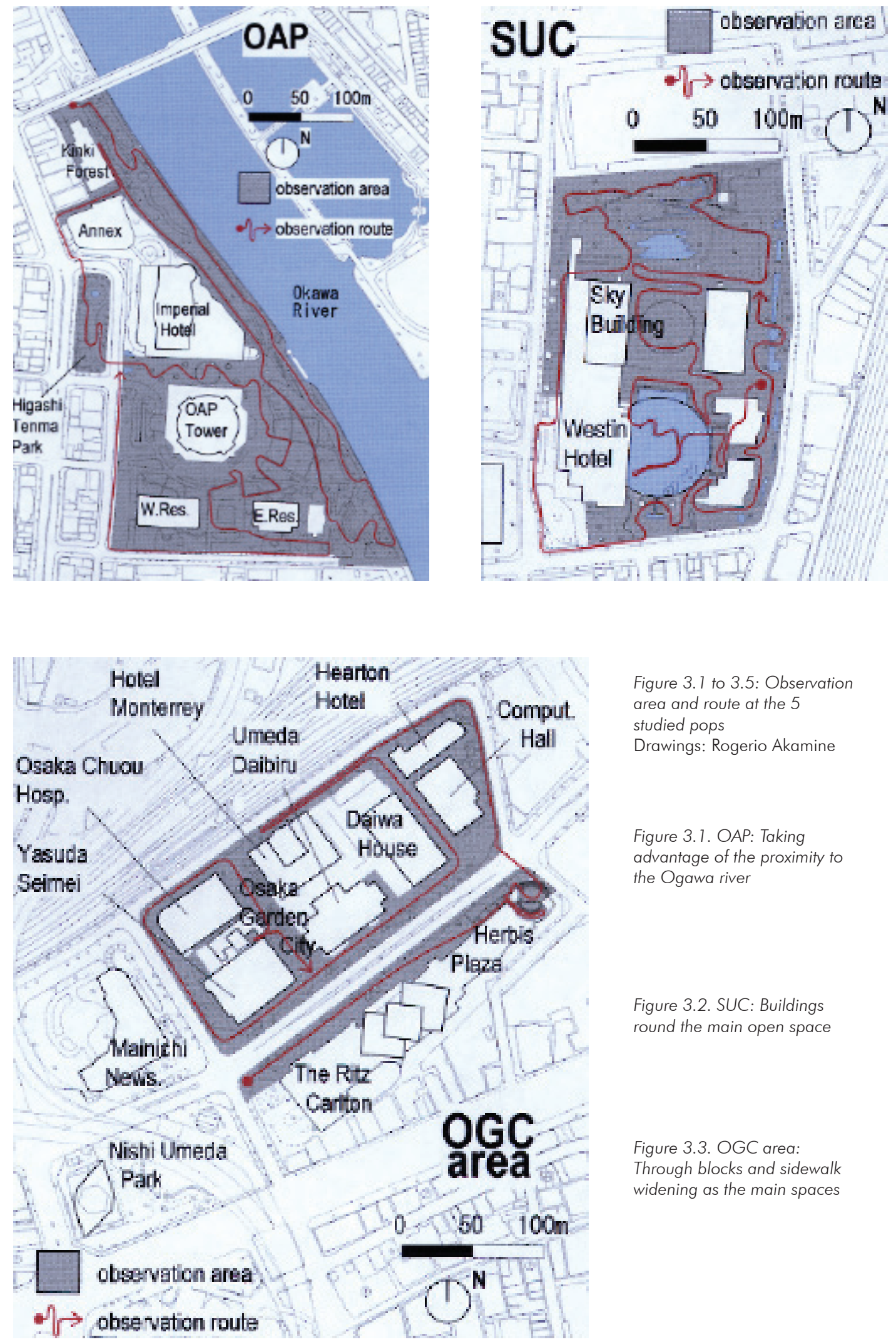

Figure 3. 1 to 3.5: Observation area and route at the 5 studied pops

Drawings: Rogerio Akamine

Figure 3. 1. OAP: Taking advantage of the proximity to the Ogawa river

Figure 3.2. SUC: Buildings round the main open space

Figure 3.3. OGC area: Through blocks and sidewalk widening as the main spaces 
Figure 3.4. ATC: Terraces goes from the bottom of the building (southwest side) until the edge of the water

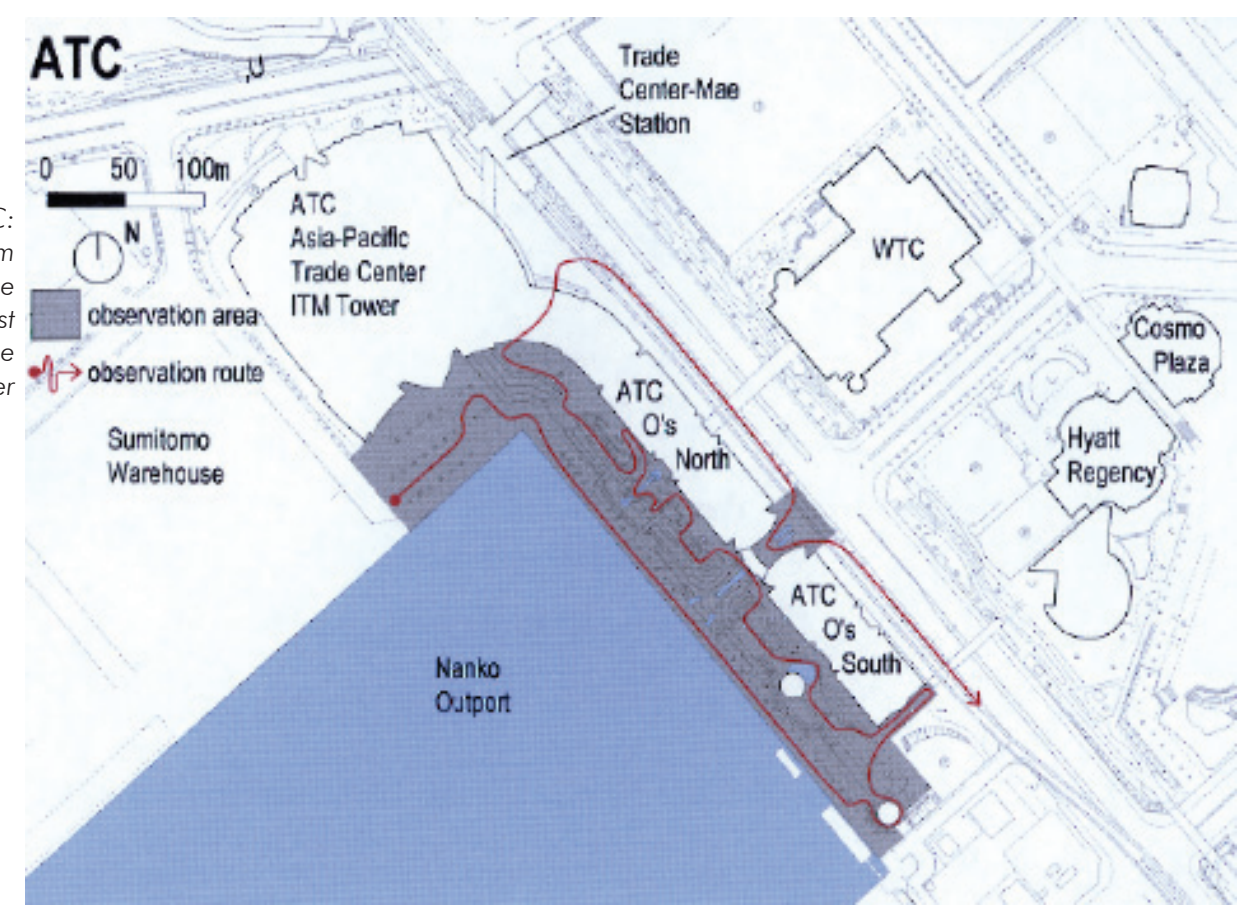

Figure 3.5. OBP:

Before the join of rivers, the wide site

is plenty of open spaces but deprived of residences

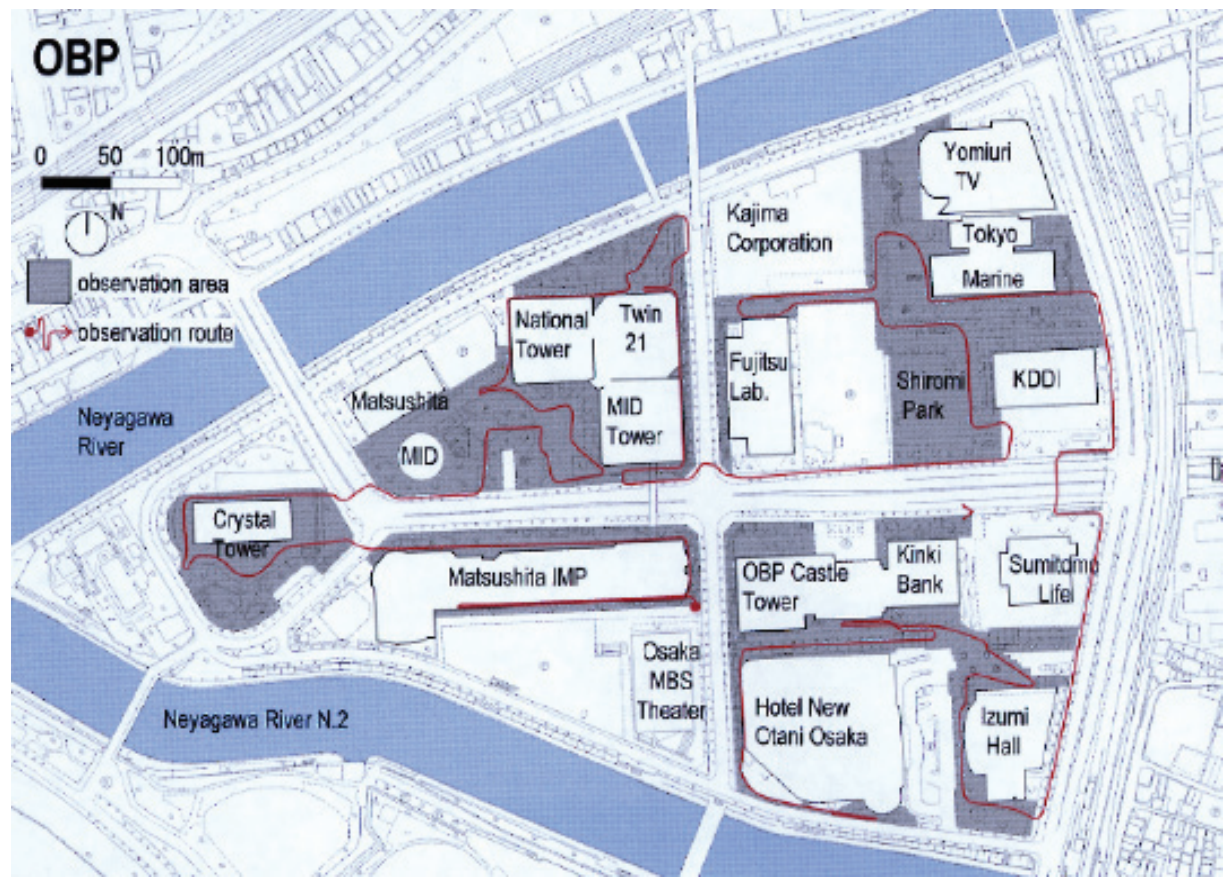


OAP (Figure 3.1; Photos 1.1 and 1.2) took place in a large site close to the Okawa river, near the Osaka castle. The main building is for offices with restaurants in the lower part, the other towers are a hotel with shops and two residential buildings. Train and subway stations are near, but not so immediately close to the site. The park along the river is linked to the open space of OAP, making a level difference soft, especially by means of the wide stairs and the amphitheater, where frequenters can sit. Some benches are disposed along the paths between the OAP building and the river. From a continuous 30 meters wide bank, people attain the view to the river with some traffic of tourist waterbuses and athletes' boats, also to the Sakuranomiya Park in the opposite bank. Sakura Hiroba is in between the office tower and the hotel building, strategically in the center of the project, where there are some sitting places under a covered area (opening: 1996).
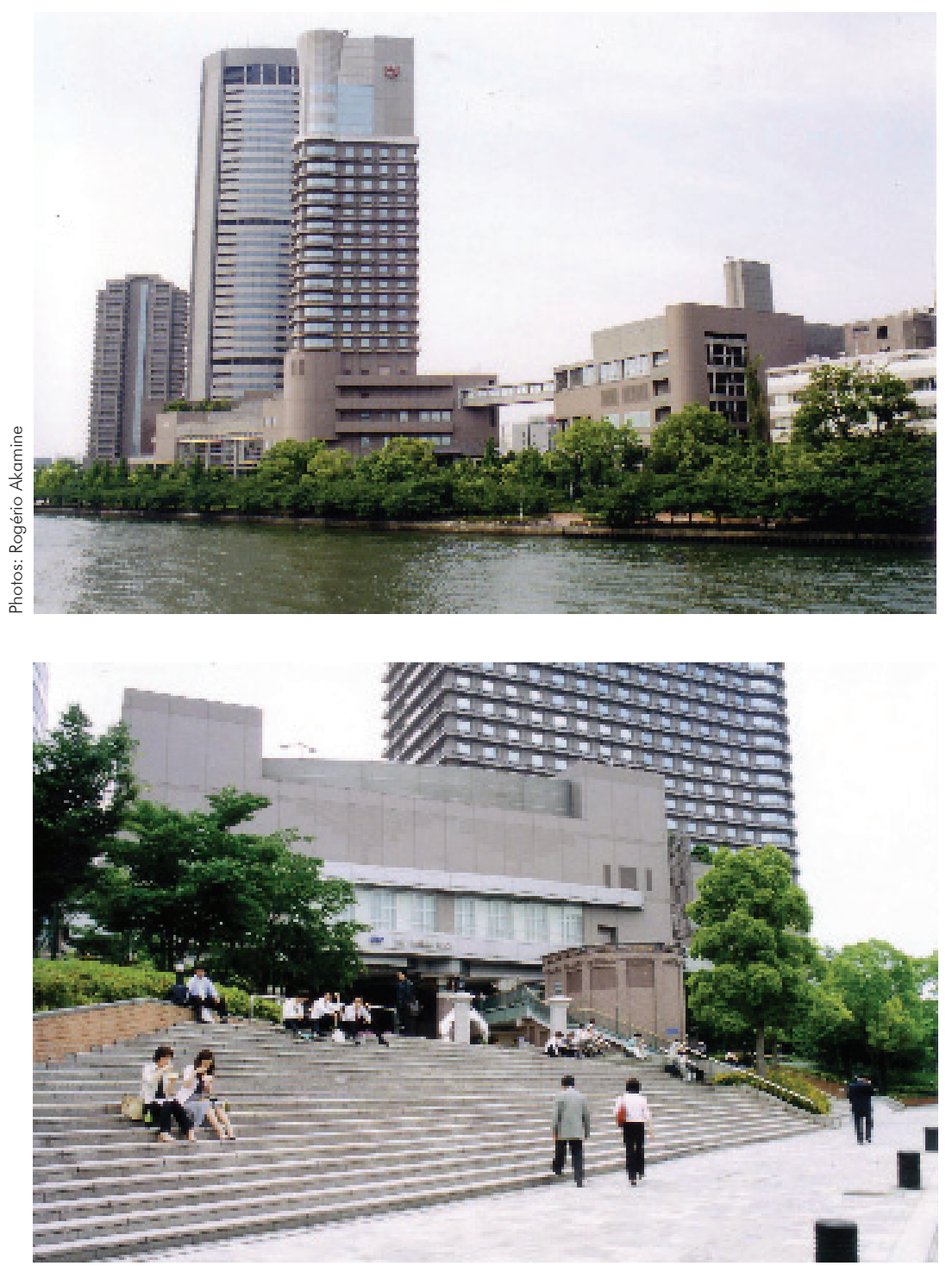

Photo 1.7:

OAP and the open space along the Okawa river

Photo 1.2:

Wide stairs makes soft difference level at OAP 
SUC (Figure 3.2; Photos 2.1 and 2.2) is near Osaka station, but a little bit isolated from the city fabric by a wide area of shunting trains and their containers yard. Pedestrians coming from important terminals of trains and subway stations reach the area usually through a 350 meters tunnel under that trains yard. Offices, convention rooms, movie theaters, shops, restaurants and a hotel are gathered around the main open space. Besides these activities, it is a tourist spot in the city because of the observatory on the top of the building. Although there is no natural scenery, a flower field and a sunken wood with waterfalls are man-made and provide a rare atmosphere for the place. There are some stone covered benches and a very long one in the middle of the open space, in brown granite (opening: 1993).

Photo 2.7:

The porch of SUC configures a central open space

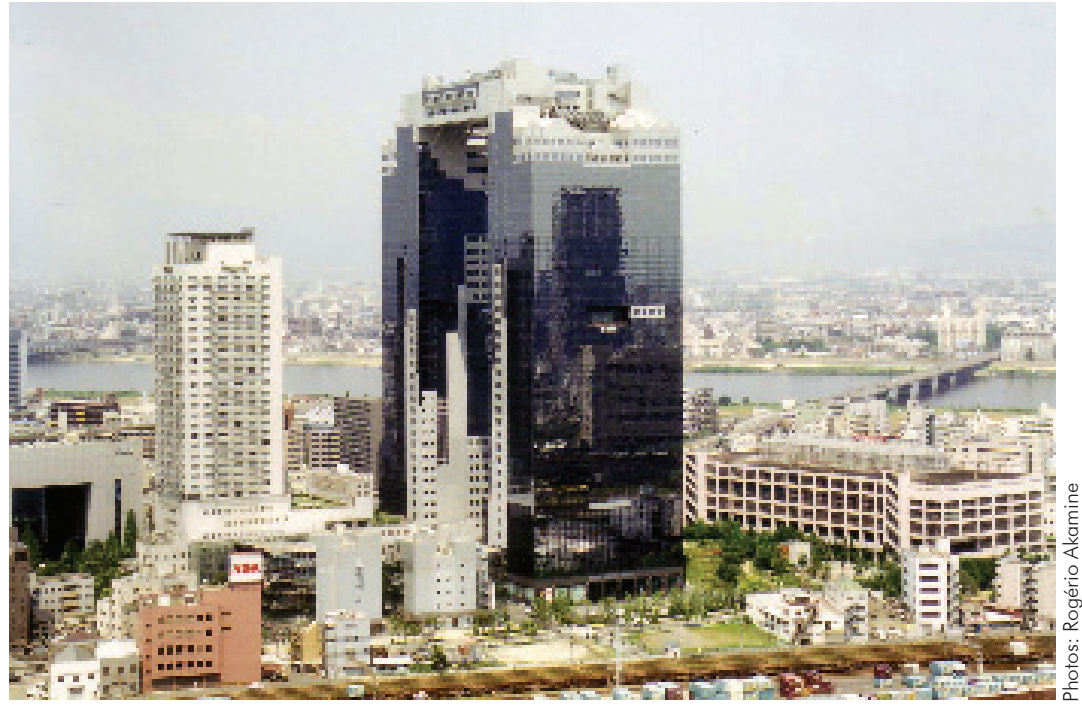

Photo 2.2: Long bench and sunken wood of SUC

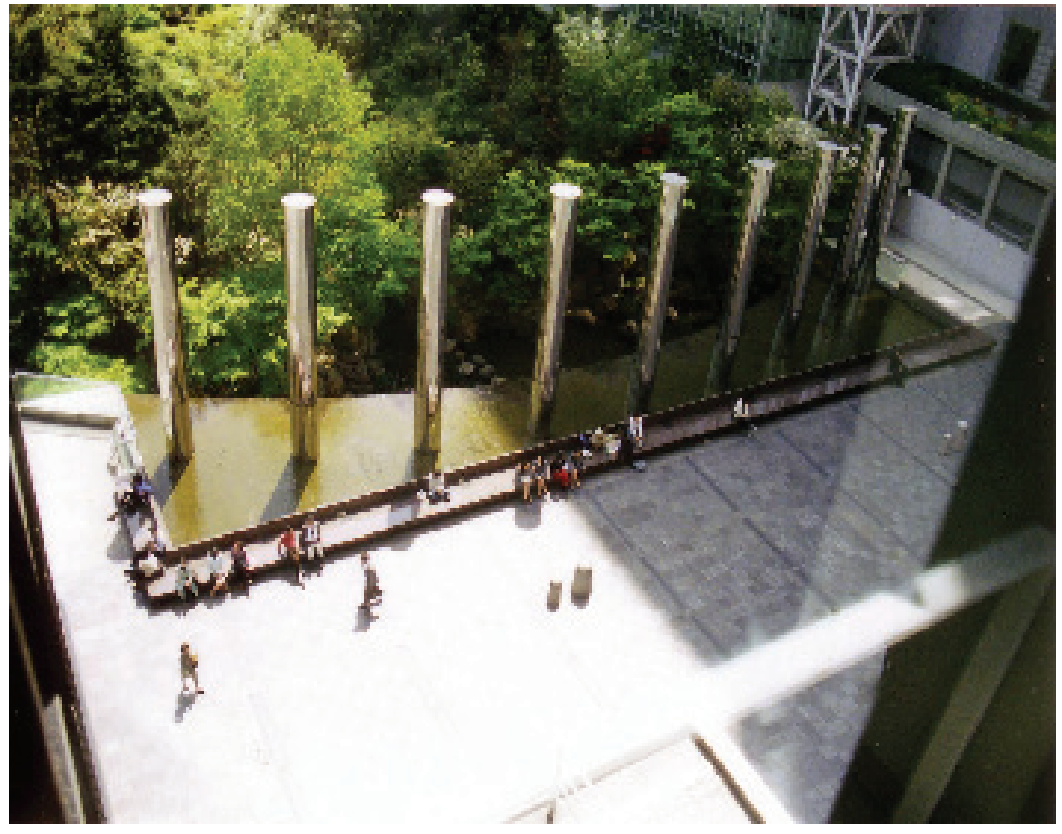


The smallest open space is the OGC area (Figure 3.3; Photos 3.1 and 3.2) in comparison to all the study cases. OGC is a complex project near Osaka station with high-rise buildings, mainly for offices. Two hotels, one hospital and one school of informatics also occupy the same block. The main open space is in a through block where the width is of about 20 meters. A café with some tables outside connects with that space and represents refreshment in the surroundings. No conventional benches are visible, but basement of sculptures, other geometrical solids and curbs end to be used as sitting places. From there, it is possible to see trains of the JR lines passing in a higher level, as a background scene. Another open space is close to the HAL Computer School, and its configuration is a corridor, about 12.5 meters wide, with sitting places along both sides. In the opposite block of OGC, the open space is a sidewalk widening between the street and a high-rise building of a hotel with a shopping mall in the lower part. Besides some benches along the sidewalk, four tables with chairs are disposed on a wood deck near the corner. On the corner, a round space similar to an amphitheatre is hung with a big screen and is divided in two parts of steps. An upper level including few benches provides a view of the whole space, even being under the screen. The other part is in the street level, but it supplies few sitting places because of its position at the entrance. Moreover, to reinforce the character of entrance and passage, escalators bring people from and to the underground floor (opening: 1997).

With a shopping mall and convention center, the building of ATC (Figure 3.4; Photos 4.1 and 4.2) connects the Trade Center-Mae Station and the Osaka World Trade Center. Through the 49 meter distance between the building and the edge to the water, terraces goes from up to down, from where it is possible to watch the movement of ships in the sea, containers being loaded, and the sunset. Some benches are aligned in the edge of the highest terrace and numerous steps can be used as sitting places. In two points, the steps

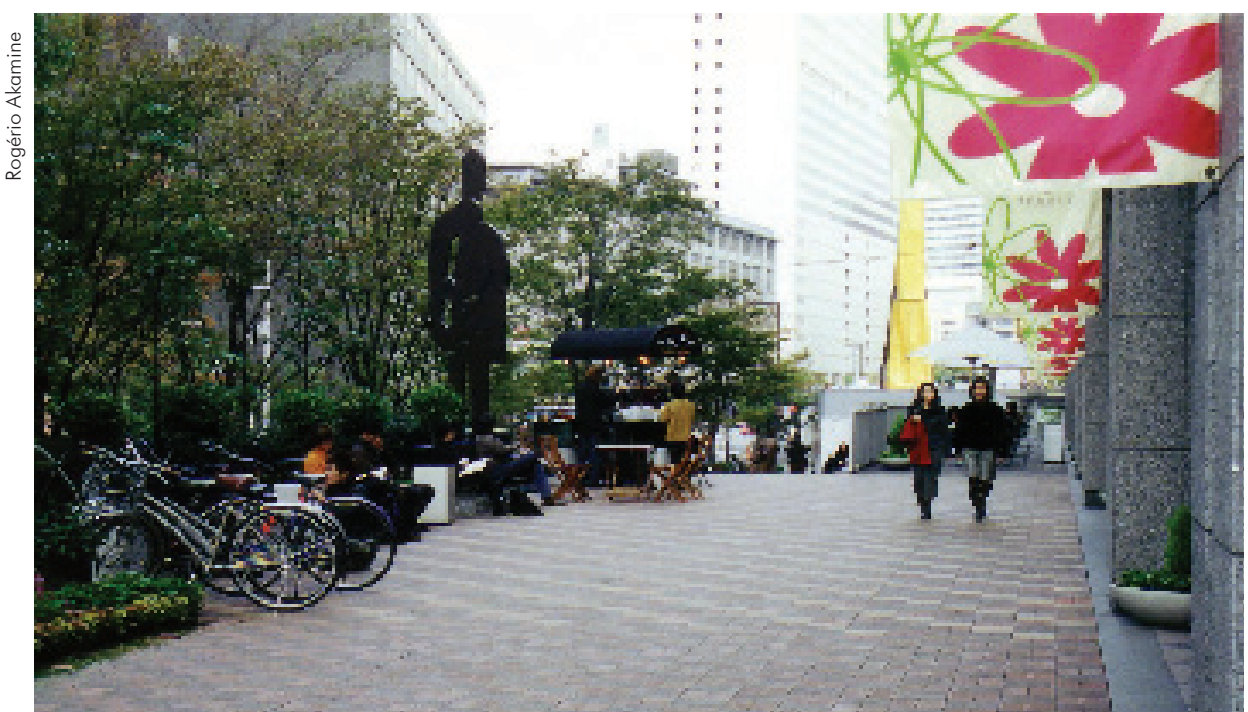

Photo 3. 1:

Sidewalk widening close to an entrance of Herbis Osaka 
Photo 3.2:

The tower of Herbis

Osaka and sidewalk widening

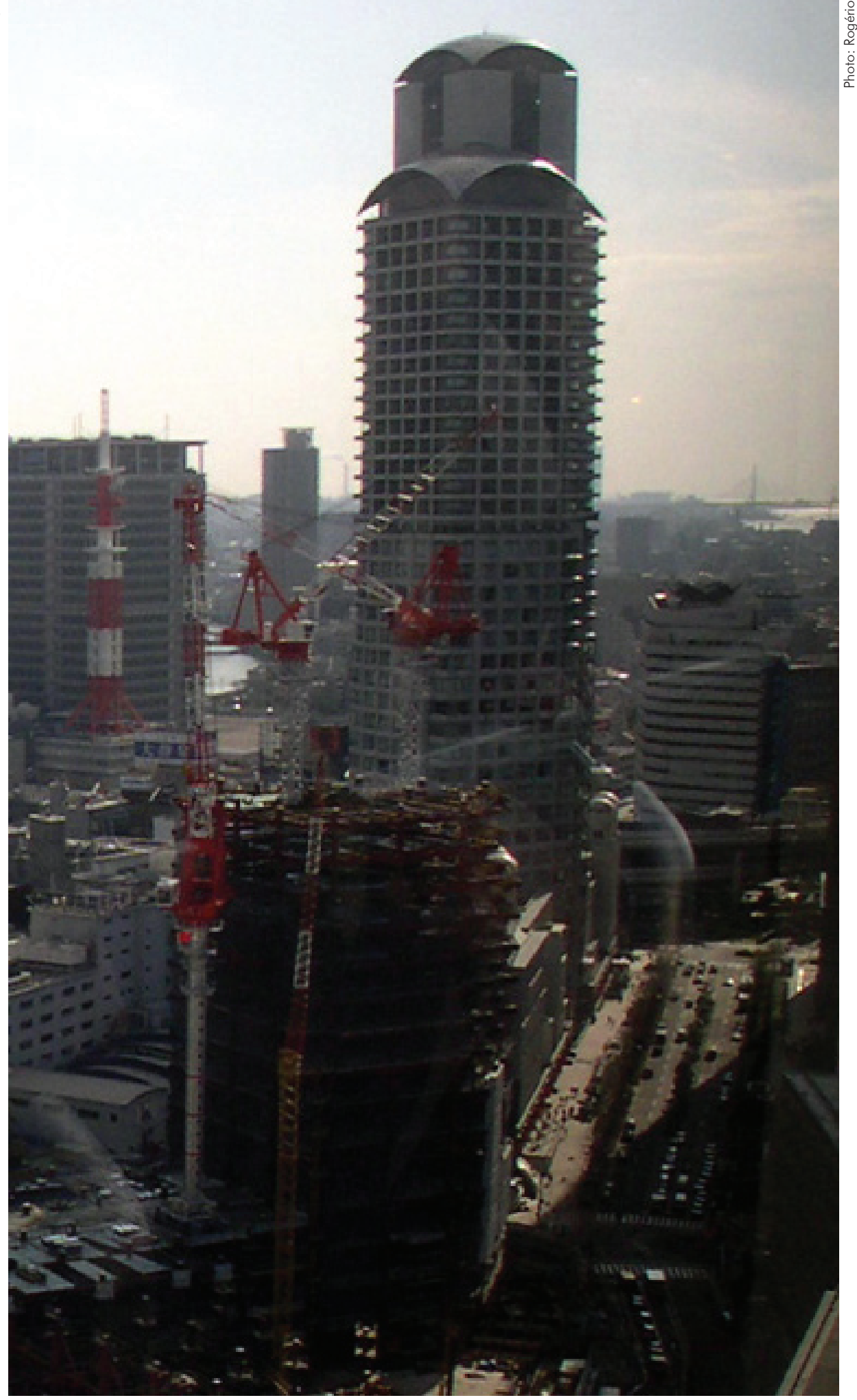


are arranged to support spectators during events such as concerts. Indoor restaurants, cafés and shops are easily accessible, whereas a heavy traffic of vehicles is in the opposite side of the building (opening: 1994).

OBP (Figure 3.5; Photos 5.1 and 5.2) has the biggest area among the five places and it is situated just before the join of the Neyagawa river and the Neyagawa river number two. Despite the existence of some bridges and an underpass, the rivers and train rails isolate the site as an island in the middle
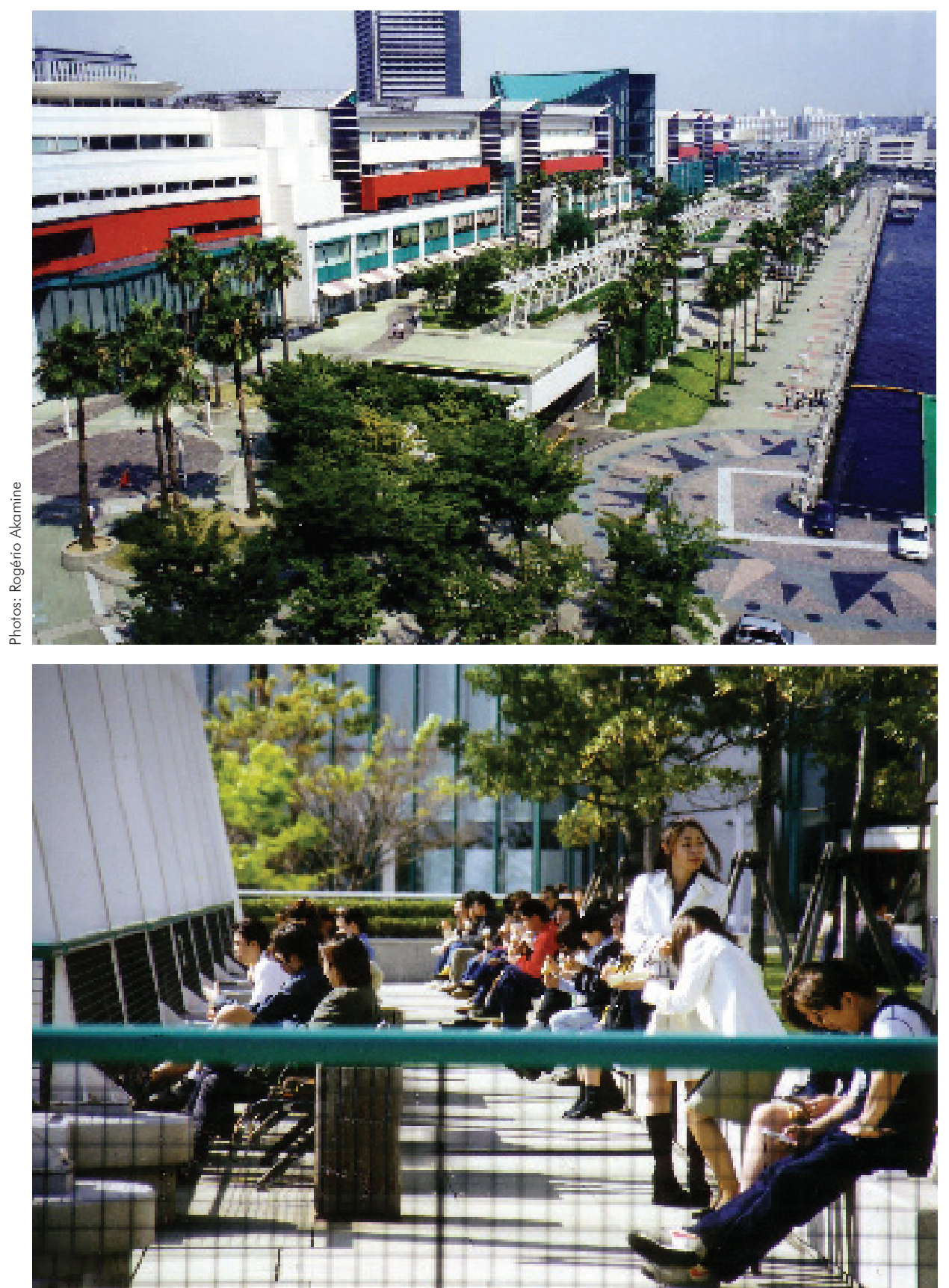

Photo 4.2. ATC: Sitting places toward the sea 
of urban fabric. There is a subway station in the area connected to a shopping mall and office tower, the building of Matsushita IMP. Nevertheless, most of people come on foot from the stations in the north of the site, crossing a special covered bridge over the Neyagawa river. To the south, there are the Osaka castle hall and the Osaka castle. People going to the Osaka castle park cross the OBP in the middle between the Twin 21 and the Fujitsu Laboratory. There is no residence, and office buildings are the majority among towers. The others are a hotel, a TV channel, and theaters, all volumes surrounded by open space. Except conventional benches that are grouped in the space between the OBP Castle Tower and the Hotel New Otani Osaka, other sitting places are ledges of planters or covered by rock (opening: 1990).

Photo 5.1: $\mathrm{OBP}$ just before the join of two rivers

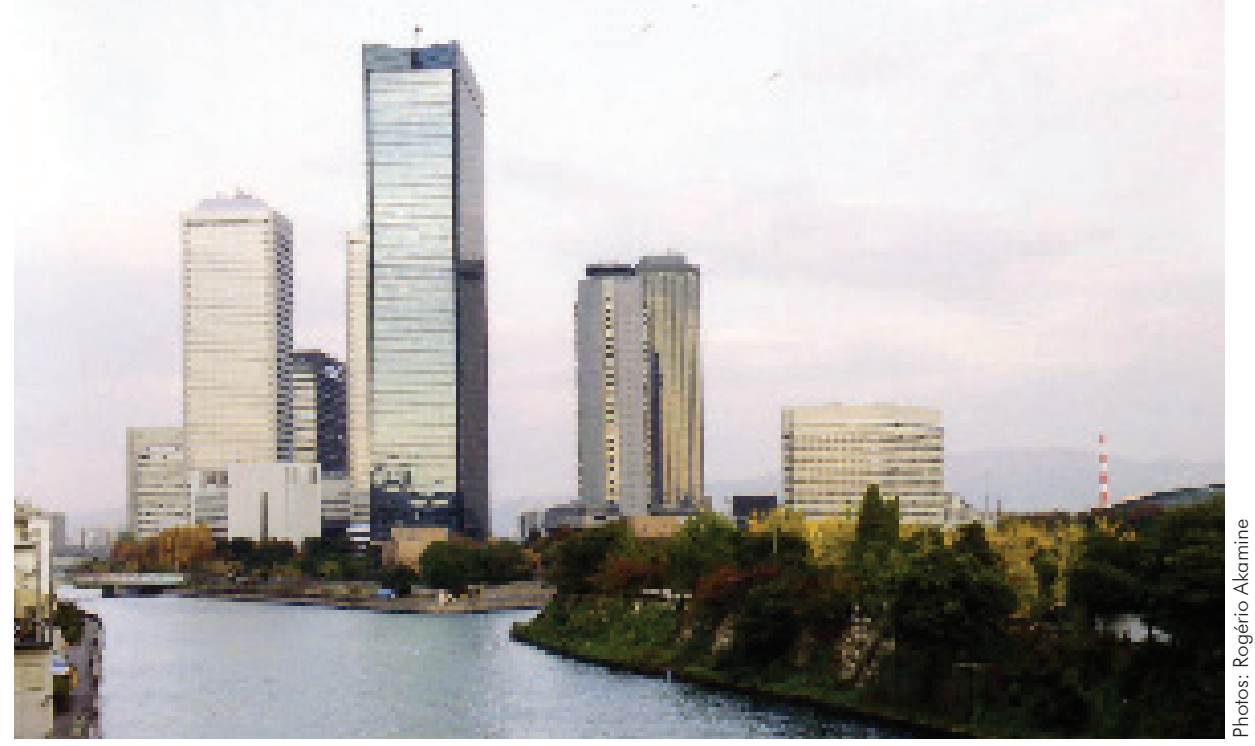

Photo 5.2:

Street to the station in the north of $O B P$

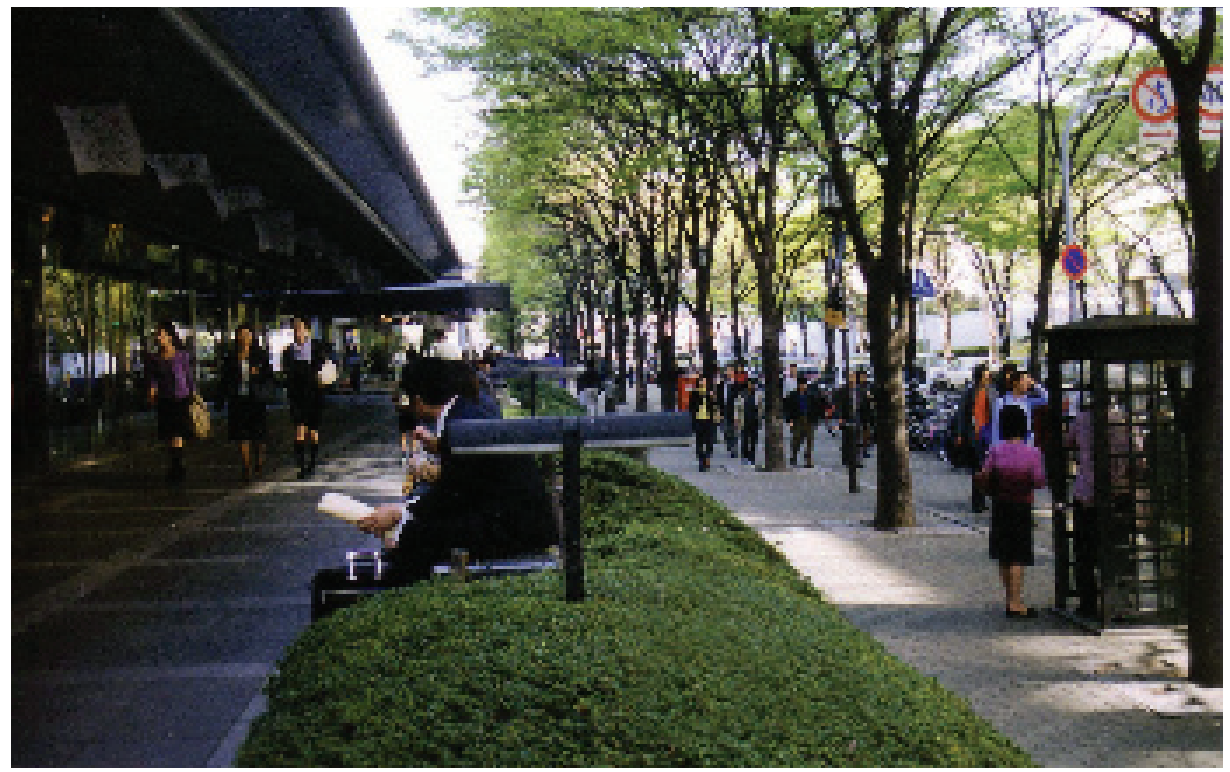


The total area of open spaces, where the observations were done, is of about 19.5 hectares. The areas are different since the smallest one at OGC area with $1.6 \mathrm{ha}$, until the biggest one at OBP, with $7.4 \mathrm{ha}$. The total number of users account to 3,630 people, with a minimum of 147 to the maximum of 804 counted people per place a day (Figure 2). There are variations in number of counted people of a weekday in relation to a weekend day. Not only increases in number of people happen, but also reductions of them according to the weekly work cycle. The most abrupt case is at ATC, where the population on weekend day increased in three times in relation to that of weekday. It is because ATC has become a destination for people looking for entertainment on weekends, for example there are more frequent concerts than the other places. In contrast, although in less intensity, the populations of OGC area and SUC decrease to half on weekend days. Those are typical business areas whose open spaces end to be used mostly on weekdays. The cases with small variation are $\mathrm{OAP}$ and $\mathrm{OBP}$, with respectively 90 and 107 percent of weekday in relation to weekend day. Both of them have the widest areas.
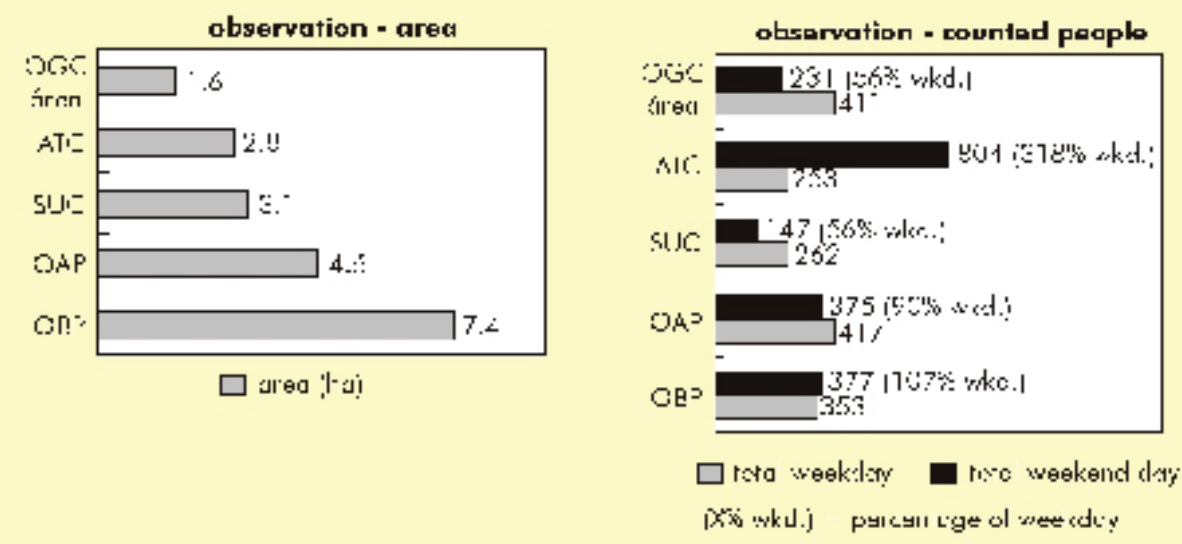

Figure 2: Observed areas and counted people

Source: Provided by the authors

Urban planners compare rate of green areas in cities to assert a relative quality in urban life. Nevertheless, with a simple examination, it is clear that the amounts of counted people are not proportional to the dimensions of the open spaces. Other analyses are necessary to discuss the real convenience of open spaces related to the use and to the benefits for city inhabitants.

\section{Attributes of Users}

The variation of population at the cases during the day was registered in five turns of observation. The first turn was at 10 o'clock, when most of the shops started to receive clients; at 12:15, it was possible to see people going out to have lunch; 15:00 was the middle of the observation period; 18:30 was the end of working day and in the sunset time; and finally at 20:00, already dark, when it was possible to see people leaving work and the movement at night. 
In order to compare five places with different areas, the user density (user per hectare) was adopted (Figure 4). The first information noted was the high density of users in the five places. One, at OGC area, exceeded 140 users per hectare during weekday, and the other, at ATC on weekend day, which exceeded 120 users per hectare. On weekend day, the density of OGC area is the second highest, while the densities at other places are more similar to each other, both on weekday and weekend day. On weekday, except for ATC, the peaks of density are at lunch time, however, on weekend day it happens a little later, at 15:00, except for the OBP case. One of the reasons can be understood later when the observed activities are analysed. The densities of SUC and OAP are very similar in number and rhythm during the day. After lunchtime, the density of users at OBP declined either on weekday or on weekend day.

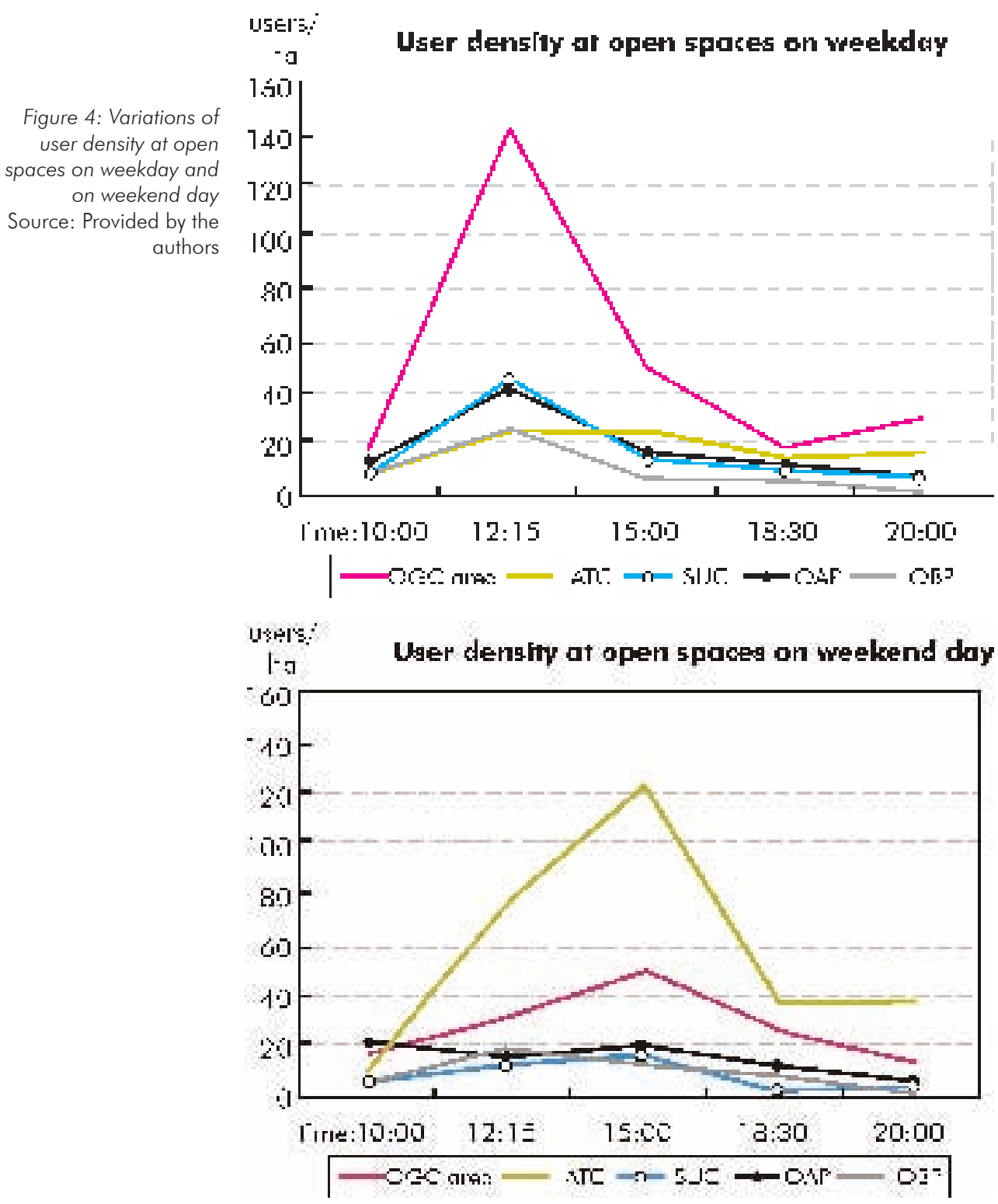


In general, the proportion of men and women at the observed open spaces are balanced, in 50 to 50 percent (Figure 5a). Only in three moments the percentage of men surpassed the 80 percent in relation to women. They were during weekday, at 10 o'clock of OGC area and at lunch time (12:15) of OAP. The isolated case when women were less than 20 percent was in the morning (10 o'clock) of OBP. Curiously, these occurrences were not at night, when women are supposed to be in small number and to avoid staying in open spaces. Some authors, such as Altman \& Zube (1989) have written about places where women felt more comfortable, especially when security seems to be more efficient with the presence of guards. Deeper investigation is necessary to affirm any relation between the presence of women and the

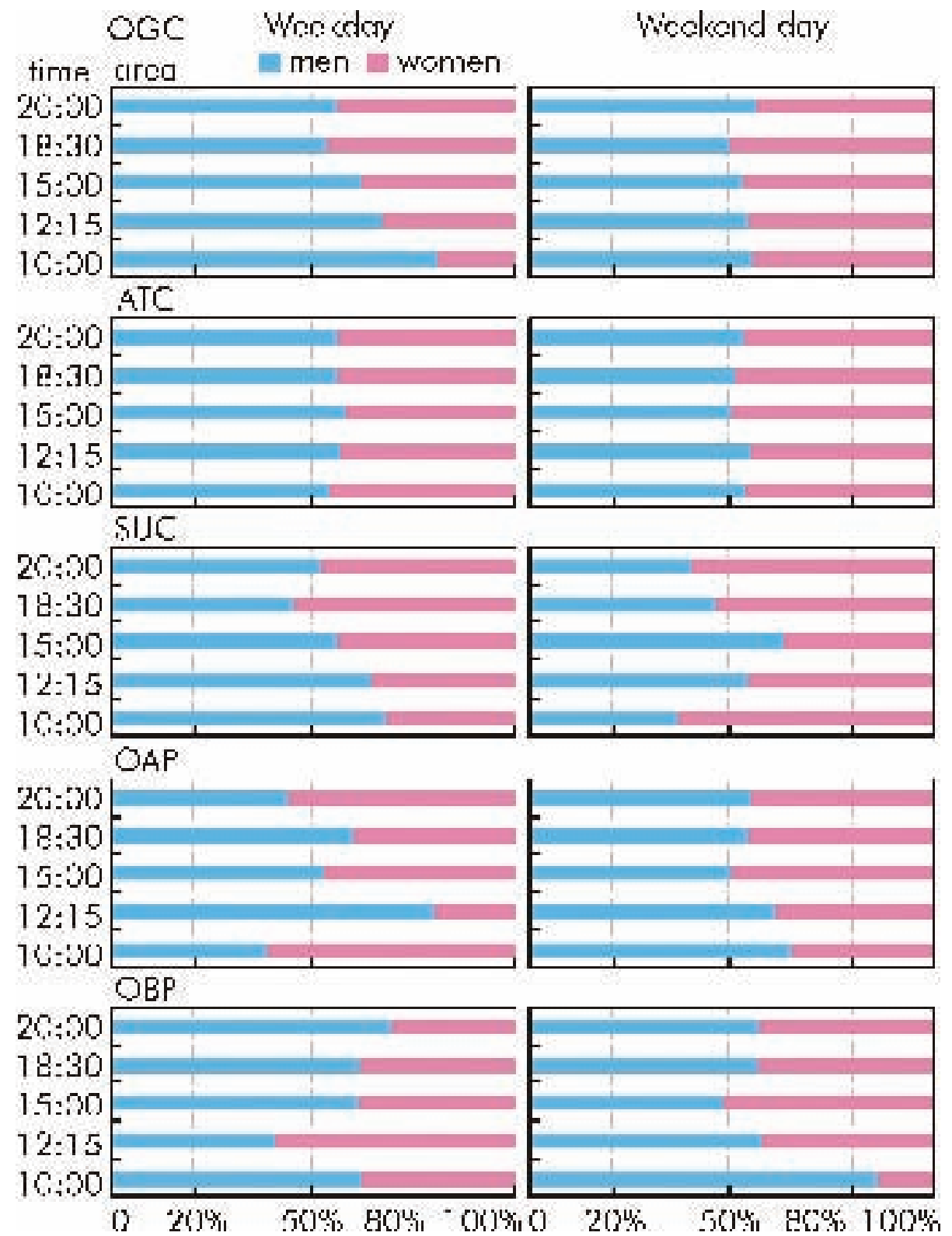


sense of security in a pops. In some moments women surpass half of the population, as the 10 o'clock of the OAP, or lunchtime at OBP on weekdays, however they have neither reached 80 percent, nor an overwhelming majority of the users in any moment.

For the present study, all users with appearance from 0 to 10 years old were considered children, from 11 to 60 , adults, and more than 60 years old, older people (Figure 5b). This definition aimed to detect who can come and stay freely at open space and the others who need care or company of other person. Children and older people are minority, but disabled people are almost totally

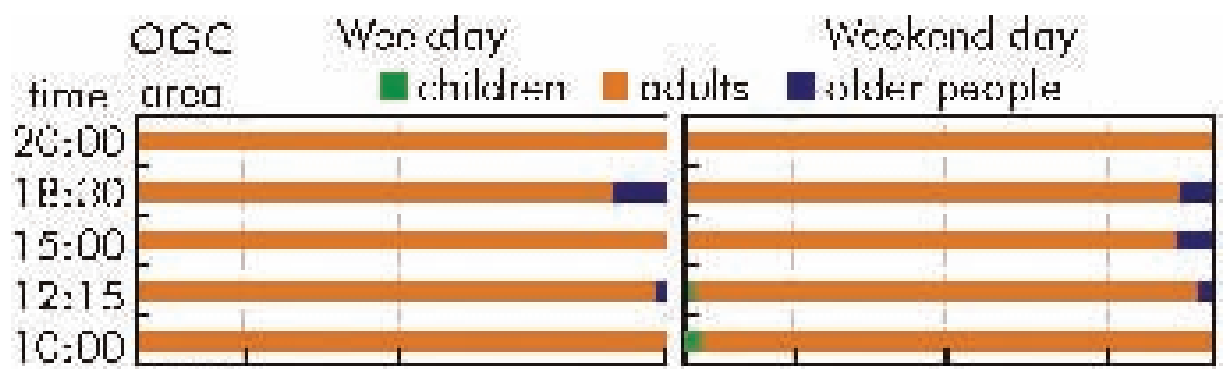

Figure 5b: Propor-

tion of childrenadults-older people on weekday and on weekend day Source: Provided by the authors

$10: 00$
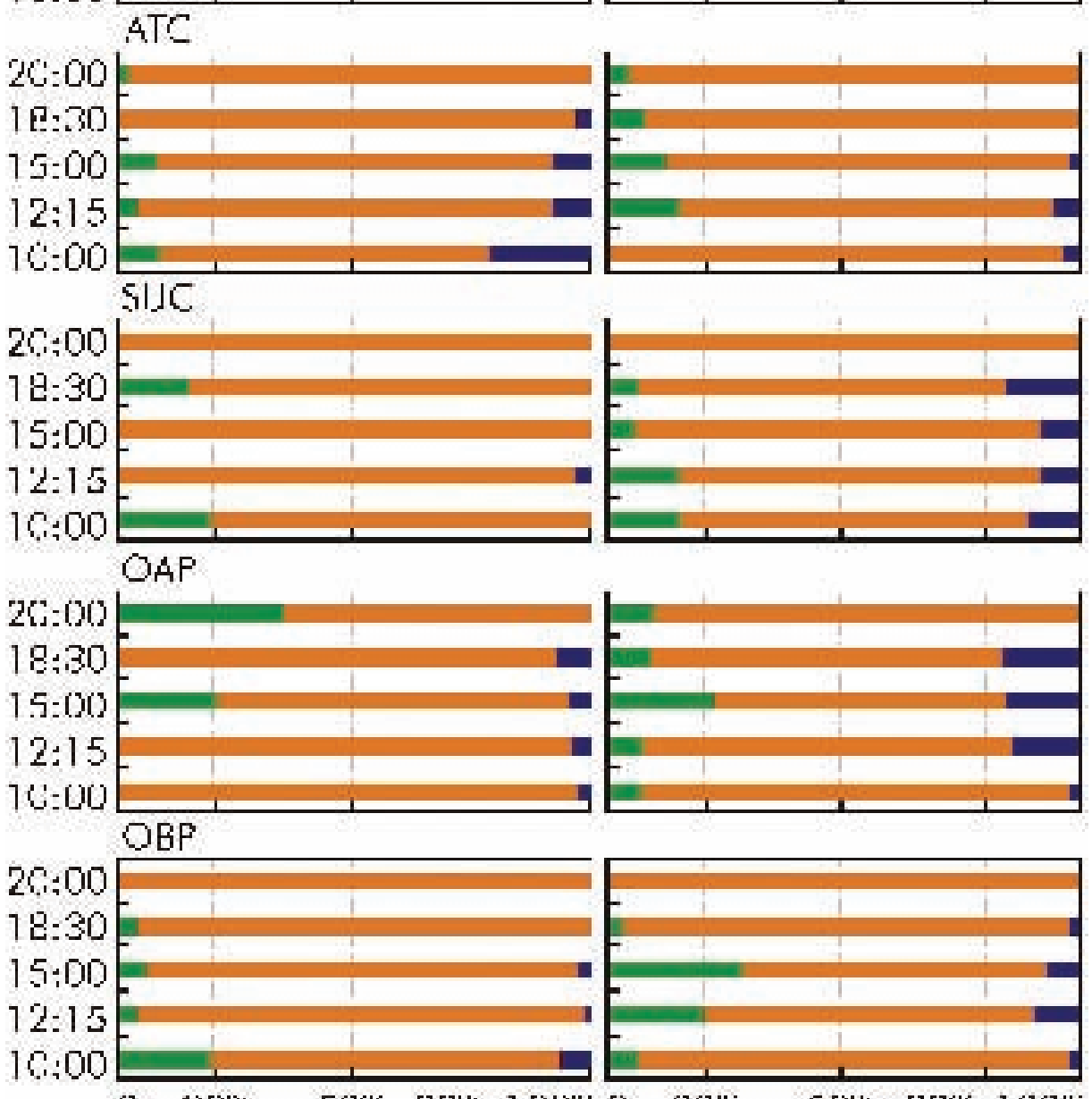

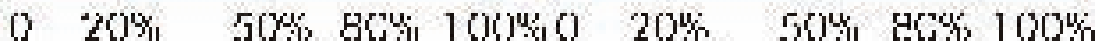


absent at those open spaces. Just two people in wheel chairs were seen with care and company of other people, but out of observation turns. One was in the morning at ATC and the other in the afternoon at OAP, both on weekday. Children presence was more frequent on weekend days than weekdays. During weekdays, a higher proportion of children might be explained by high decreases in proportions of adults in working time (SUC at 10 and 18:30, OAP at 15 and 20, and 10 o'clock of OBP). Older people are also more present during weekend days, with an exception at ATC on weekday with a peak passing the 20 percent in the morning. OGC area (weekday and weekend day) and OBP (weekday) had the lowest numbers of children and older people. Practically, neither children nor older people were found at any of the observed places at 20 hours. Pops should be more convenient for the use of children, disabled and older people.

During observations at open spaces, it is possible to find people alone, couples, three people or more (Figure 6). The question here might be in which proportion these groups account relatively among places in this study. Two-people type at the open space of ATC is peculiar both on weekday and weekend day; they represent at least half of each sample. In the same way, one person alone is peculiar of OAP open space. On the one hand, considering weekday, SUC, OAP and OBP have more than 50 percent of person alone. On the other hand, on weekend day, two-people type is the majority at ATC and SUC. OGC area (weekend day and weekday) and OBP (weekend day) are roughly balanced in person alone, two people, and three people or more, about one third each part. Big groups as those of families or workmates are not common at the five open spaces. Pragmatically, this information can support the design project to define furniture and their arrangement, as well as dimensions of paths, etc. The size of all groups should be supplied by versatile layouts, for multiple possibilities of groups to sit. Sometimes, as the east and south parts of the OAP office tower, spaces with excessive large dimensions are defined neither as a passage, nor as a place to stay.

In the last three observed cases, OGC area, OAP and OBP, the appearance of adult people was registered according to their formality in dressing (Figure 7), for example, people that wear formally (suits) - formal - and others that wear informally (blue jeans or jogging clothes) - non-formal -. It might be an indicative to think about proportions of people who are more probably related to business in an area, during working time, and others less probable to have work in the nearby buildings.

On weekday, the peak at lunch time was of non-formal men at OGC area. It was due to the students of the Informatics School having a break. Formal dressed people are the second most numerous. At OAP, men wearing suit passed 100 people and non-formal women had an inversion with formal ones at the lunch time. OBP had peak at lunch time with formal women with almost 100 of them. 
Figure 6: Users in groups Surce: Provided by the authors
Weekday

OGC
area

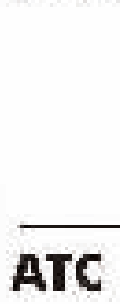

SUC

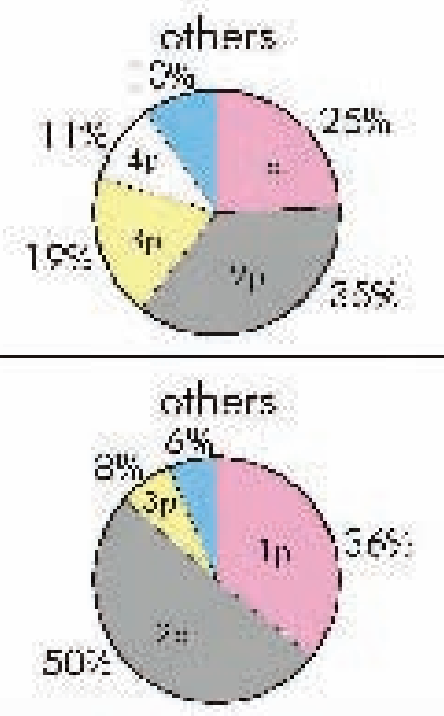

othors

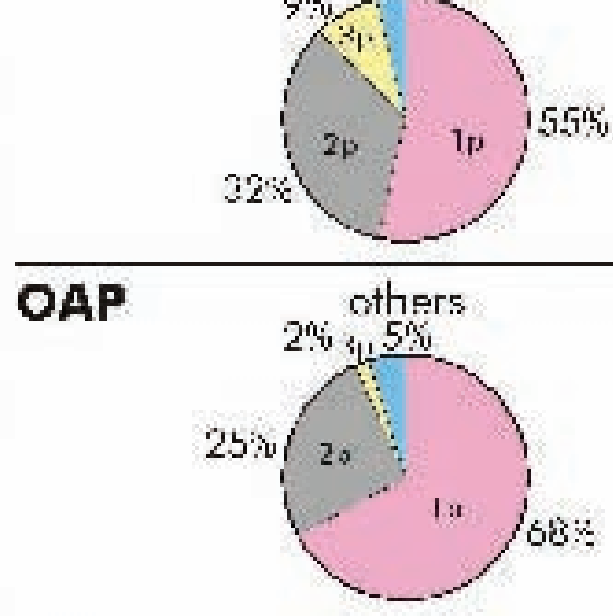

OPB

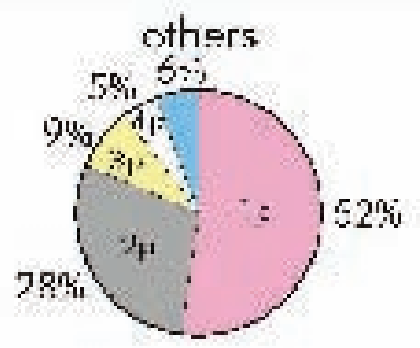

Wockond day
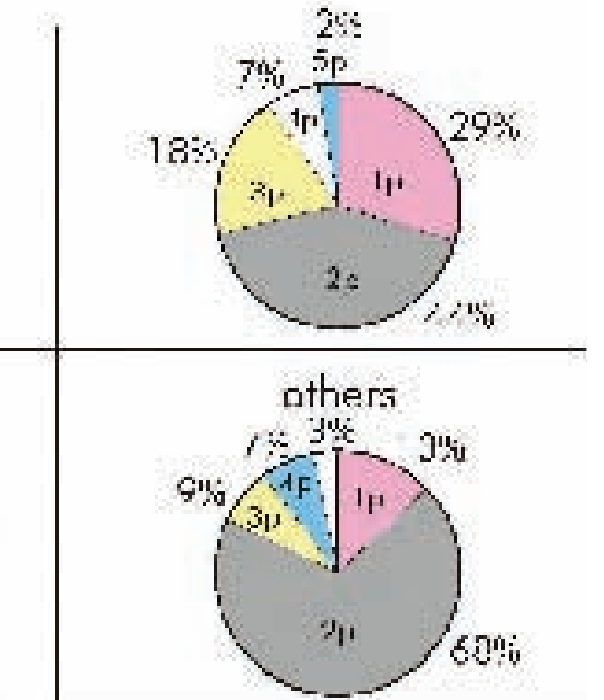

others
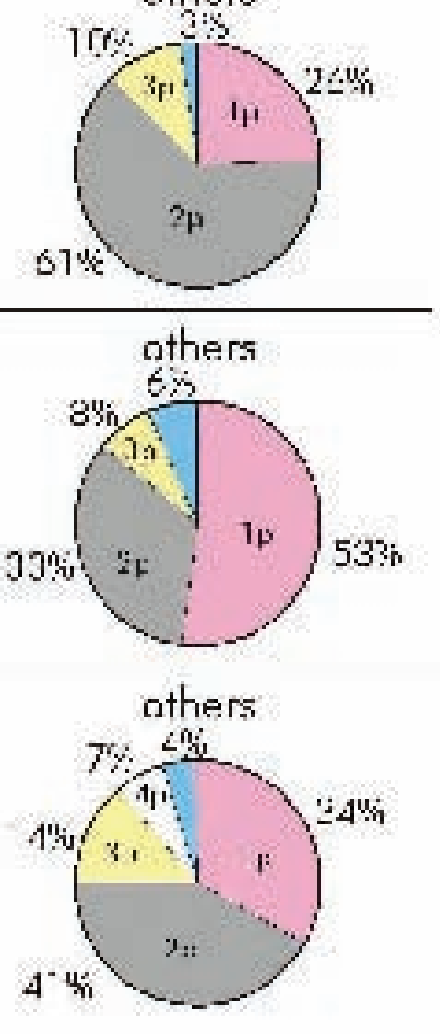

$$
1 p=\text { person a onz; } 17 F=\text { number of people }
$$




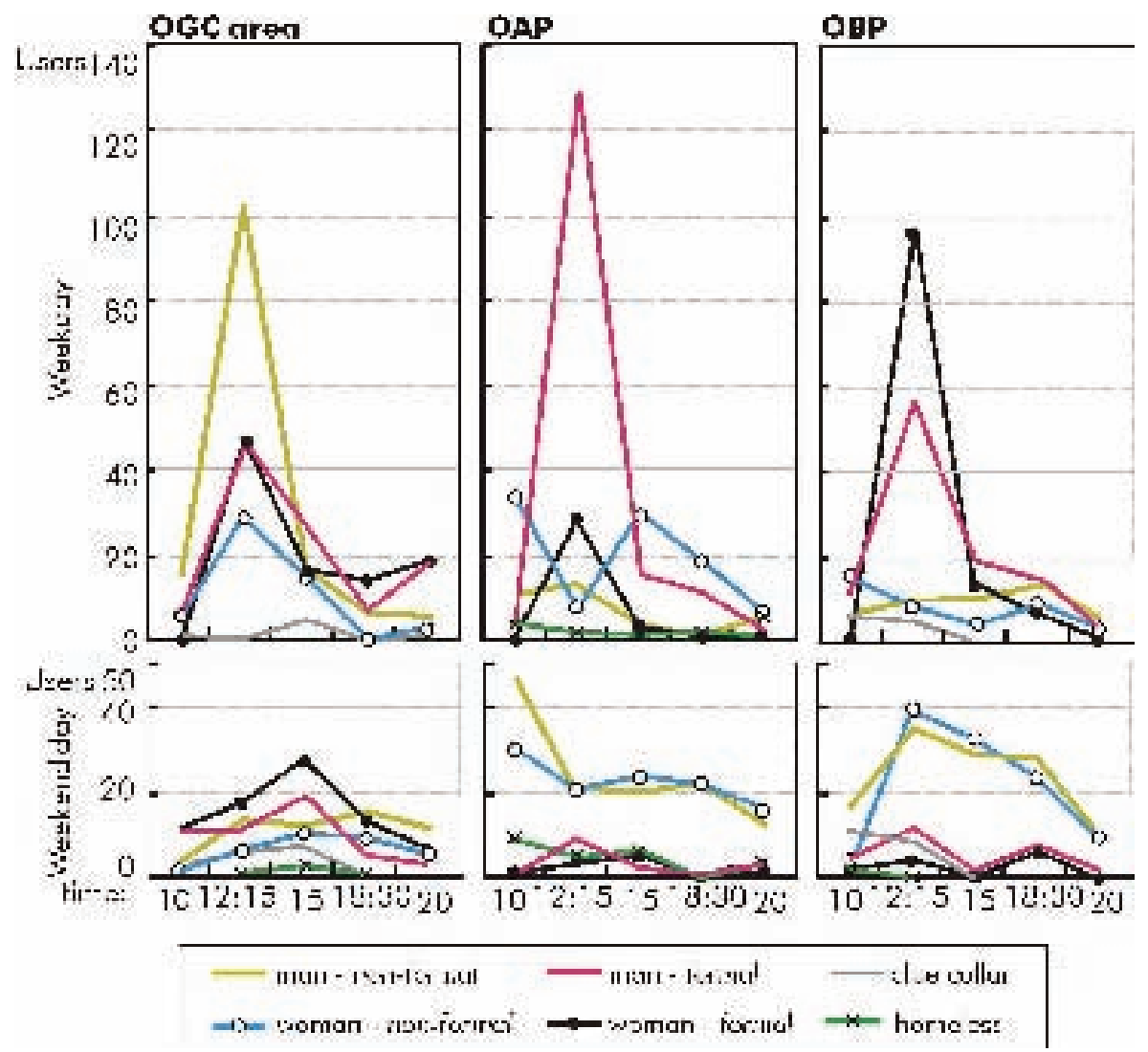

Figure 7: Adult users at open spaces Source: Provided by the authors

On weekend days, besides the decrease of users at the three open spaces, only at $\mathrm{OAP}$ and $\mathrm{OBP}$, non-formal dressed people were superior in number (but less than 50 people). OGC area had the fewest people in non-formal dressing. People with homeless appearance were proportionally insignificant. Those of OAP were out of the private land limits, and in the sidewalk of the Herbis Plaza at the OGC area. The blue collars were identified by uniforms of companies, in small amounts and they were not present in all turns of observation.

Inferior in number than the formal ones, if the non-formal people are not eventual visitors coming from other neighborhoods, they are the neighbors, the most affected with the changes of zoning regulations that is involved in the public-private negotiations. The formal people appeared in majority, whereas the non-formal was relatively smaller in number. This panorama leads to wonder about how effective neighbors of the analysed cases use open spaces of pops.

\section{Activities At Pops}

In order to systematize the analysis, activities were divided in two categories, "primary" and "secondary" uses. The first group (Figure 8) is composed by easy classifying uses: sitting, standing, strolling, lying and squatting. Users were 
mainly sitting (a), both on weekday and on weekend day. The exceptions are SUC and OAP on weekend days, when people were also standing (b) and strolling (c) in considerable proportions. In these two occasions, strolling was significant due to convenient places for that; it means paths to walk calmly. Besides homeless people sleeping on benches, lying $(d)$ is practiced by people on lawns to sunbathe, such as at ATC. Standing is a very instable activity in a space; it can avoid long talking. Squatting (e) probably happens, when people do not or can not sit conveniently and become tired to stand. An example of this is the fact that some people at OAP (3\% on weekday) bring their dogs to walk and extend a chat with others who are doing the same thing.

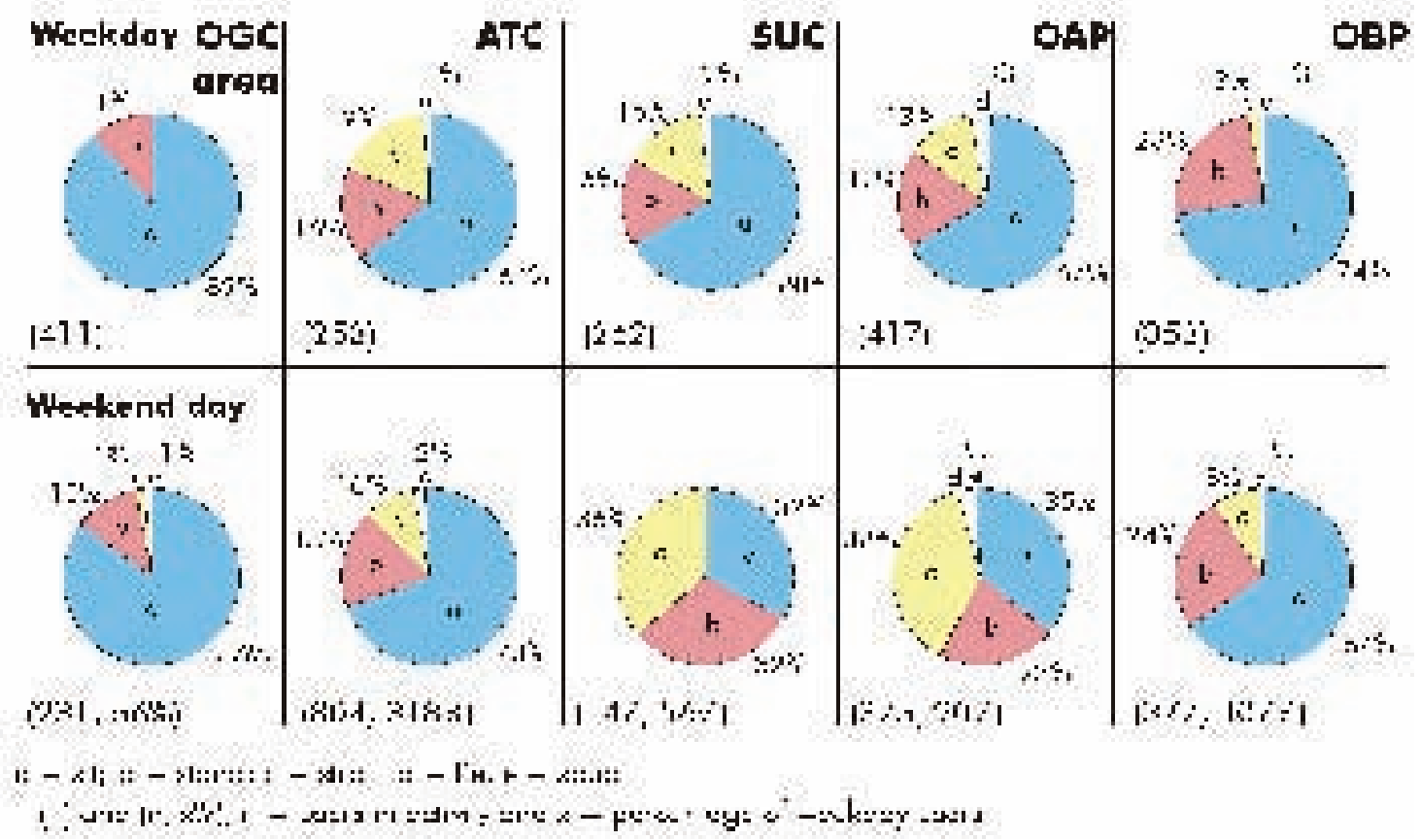

Figure 8: Primary uses at open spaces

Source: Provided by the authors

The secondary uses are complementary to the primary uses in most cases (Figure 9). Comparatively, the weekly cycle variations in amounts of primary uses are not so strong as in those of the secondary uses. Occurring outside buildings, as being inside the stress of urban life is heavier, the activities are essentially for relaxing, so eating and talking are common especially on weekdays. Many office workers were having lunch when registered, and that explains the peaks of user population at lunchtime shown above in section 5 . The amount of activities at OAP open space are relatively less heterogeneous, as the highest proportion did not reach 20 percent, while at others, some activities passed the 30 percent. Moreover, the "others" group of OAP is the highest including activities such as seeing scene, writing or drawing, sleeping, and skating or cycling. In such circumstances, the possibility of multipurpose 
use may indicate a superior quality in design of OAP open space. Peculiar features of each open space are evidenced with high proportions, as drinking at OGC area, dating at ATC and walking a dog at OAP. On the contrary, the absolute absence of an activity might be a deficiency of an open space, such as playing at OGC area which occurs neither on weekday nor on weekend day. People should be asked why they do not use certain open spaces and the reasons to use others; which need for using pops do not satisfy; and suggestions to improve configuration and equipment for open space.

\begin{tabular}{|c|c|c|c|c|c|c|c|c|}
\hline & $\begin{array}{l}\text { OG6 } \\
\text { area } 434 i\end{array}$ & ATC (175) & \multicolumn{2}{|c|}{ SUc $i 22$} & \multicolumn{2}{|c|}{ OAP [368j } & \multicolumn{2}{|c|}{ OBF $3 E$ : } \\
\hline 11. athes & E T.4 & $1.9=$ & E & $9.0 \%$ & 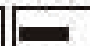 & $8.8 \div$ & $=$ & $5.5 \mathrm{H}$ \\
\hline J. $w<. c u g$ & $5.2 \mathrm{x}$ & c. & - & 3.27. & $E$ & $2 . \underline{4}$ & 1 & $1.1 \mathrm{~s}$ \\
\hline 9. wiuk & $1 \div 48$ & $0.0 \%$ & & $\mathrm{~L} .2 \div$ & 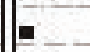 & ․ 3 & & $4.6 \mathrm{~g}$ \\
\hline a. ploj & 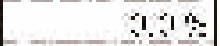 & cos & & 17 & 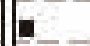 & $\therefore 3$ & $=$ & 5.23 \\
\hline 5 เ & $5.1 \%$ & cofi- & Eiv & กถ & E & $-9 \div$. & E & 7.44 \\
\hline 6. r.atr: & $3 . \bar{z} \mathrm{x}$ & $5.3 \%$. & $=$ & $6.2 \overline{1}$. & . & $1 . \leq 4$. & I & $1.1 \times$ \\
\hline 5. mai- & $\overline{0} . \bar{z}$ & $0.6 \%$ & $=$ & $1 \div$ & 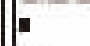 & $3.0 \times 6$ & E & 4.19 \\
\hline$\angle, r=3$ & $2.5 \%$ & $20 \%$ & $=$ & $60 \%$ & - & 253 & $=$ & $2.39 ;$ \\
\hline 3. arroke & $0.5 \stackrel{5}{0.5}$ & ? $\mathrm{c}: \mathrm{i}$ & $=$ & a? $;$ & 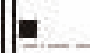 & $\bar{z} \div$ & $=$ & $11.2 \div 5$ \\
\hline 2. - clk & - 3.1 & $27.3 ;$ & $-=$ & $2 C .9=$ & E & 0.9 .5 & $-\infty$ & 22.75 \\
\hline I exा & $\begin{array}{ll}0.8 \\
0\end{array}$ & $32.4 \%$ & 世 & $2 y .9 \div$ & $E$ & प. 03 & 巨. & $30.5 \%$ \\
\hline & $\begin{array}{l}\text { OGC area } \\
17 \%, 50 \mathrm{C}_{\text {ii }}\end{array}$ & $\begin{array}{l}\text { ATC } \\
14: 7,721 \% \text { ii }\end{array}$ & su & ${ }^{1 C}$ & o) & 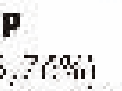 & $\begin{array}{l}\text { o日 } \\
\mid 3.21\end{array}$ & Pro:iil \\
\hline 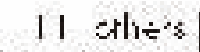 & $6 \% 8$ & 2.59 & 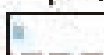 & $3.5 \%$ & & $34.1 \geqslant$ & 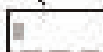 & 4.59 \\
\hline 0. whe ceg & $(.5 \%$ & $25 \%$ & & 64 & $E$ & 40 & - & $2.5 \%$ \\
\hline$=9$. orinle & $15 . \overline{8}$ & 5.5 & - & $\overline{5}$ & 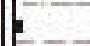 & $6, \overline{7} ;$ & $a^{-}$ & $2.5 \div$ \\
\hline 3. Flex & 5 & $3.7 \div$ & f & $3.5 \%$ & $E$ & $2.5=$ & E & $5.4 \div$ \\
\hline T $7.0 \mathrm{u}$ & $\therefore \overline{8}$ & $0 . \%$ & E & $2.3 \%$ & E & 2.10 & & $4 \%$ \\
\hline$\Xi \quad 3, c a t e$ & $\therefore 5 \%$ & 11.:8: & 1 & .98 & E & 210 & $=$ & s.5: \\
\hline 3. * & 1.61 & $1.7 \div$ & $r$ & 5 & - & $1 \pi$ & $\overline{1}$ & $6.5 \div$ \\
\hline$\exists$ i. ranr. & $4 . \dot{3} \div$ & 0.3 י. & 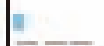 & $3.5 \%$ & 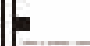 & $3.6=i$. & $=$ & 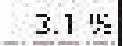 \\
\hline 3. smokn & 15.28 & $\because \bar{x}$ & $=$ & 17.28 & F- & $3.6 \%$ & $\overline{1}$ & 5.18 \\
\hline 2. $\mathrm{t} \cdot \mathrm{lk}$ & I 24.28 & 1‥ & -1 & $45.5 \%$ & = & $5.9 \%$ & $=-2$ & $27.1:$ \\
\hline נינ & 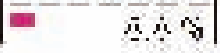 & $\therefore 8.1 \%$ & F- & $15.2 \%$ & $\|$ & 023 & $-\infty$ & 1.59 \\
\hline
\end{tabular}

Figure 9: Secondary uses at open spaces

Source: Provided by the authors

\section{Preferred Places: Sitting Near Entrances And Spaces With Views}

Some places are more used than others in a same open space. In order to make clear the preferred places, the various registrations on map of user presence during a day were overlaid (Figures 10.1 to 10.5). In the drawing, the darker the "registered users" the more used a place is. Generally, sitting places are provided in those parts. However, other aspects may be related to explain such a preference. 


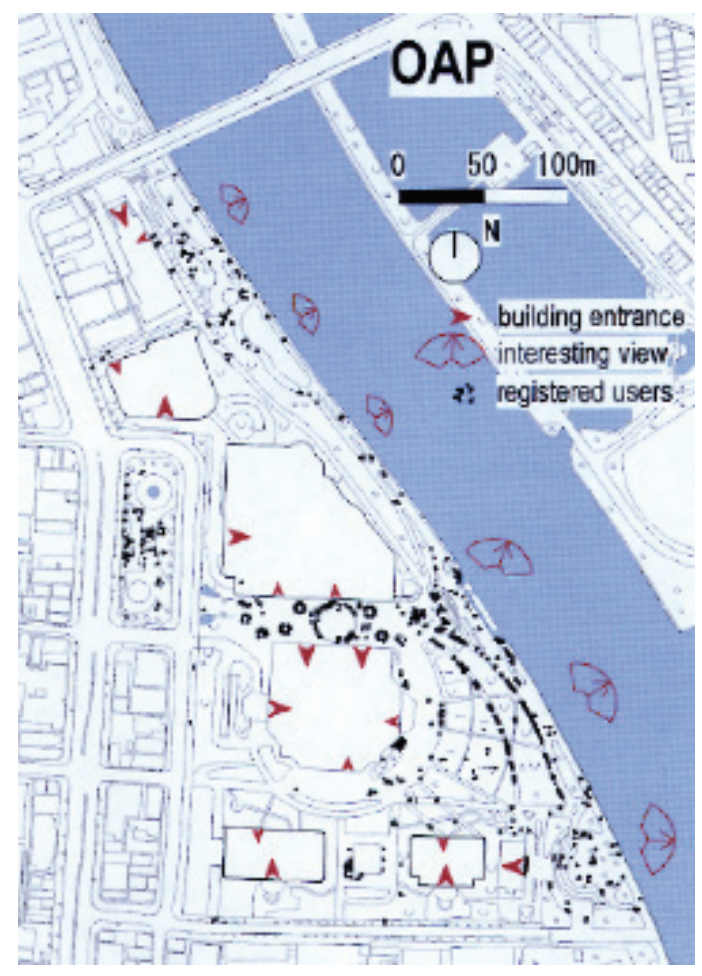

Figure 10.1: Mapping of users (overlay), views and entrances. OPA: Attaining the river scene Source: Provided by the authors

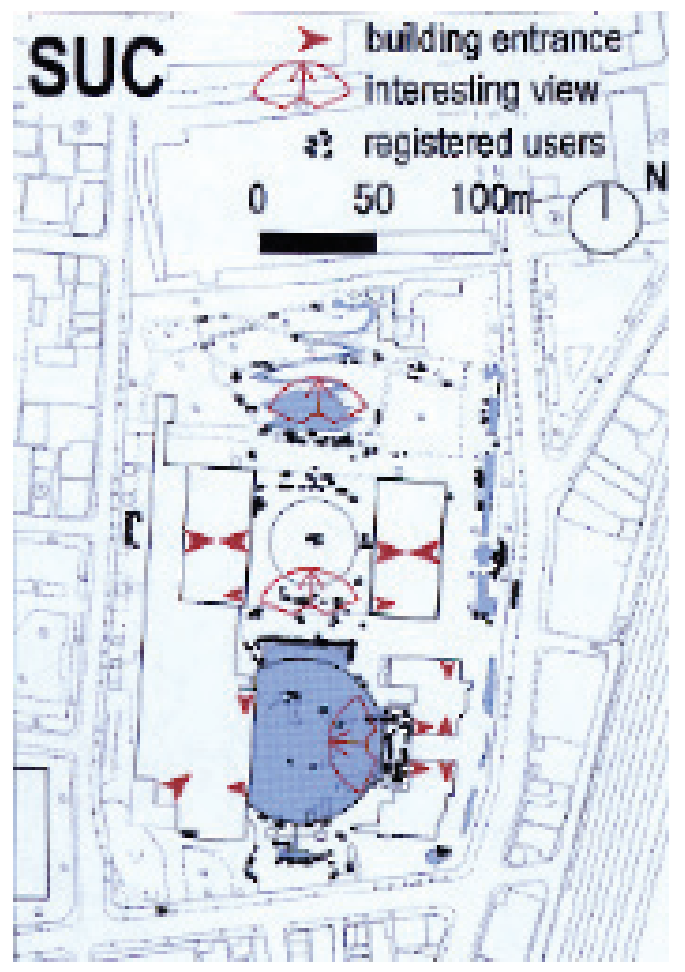

Figure 10.2: Mapping of users (overlay), views and entrances. SUC: Views of created nature Source: Provided by the authors

Oscar Newman (1973) relates design characteristics with crime statistics and concludes that some building patterns afford ${ }^{12}$ criminal activity more readily than others. In a related sense, Hillier (1996) discusses urban security by configurations including interface between moving strangers and inhabitants in their windows and entrances ${ }^{13}$. A hypothesis of the present study is that the proximity of sitting places near entrances of buildings or commercial activities contributes positively to the staying at certain portions of open space of pops (Figures 10.1 to 10.5). At OAP, the space between the OAP Towers and the Imperial Hotel has four entrances and had significant registration of users on mapping. At SUC, the entrances in two towers of the Sky Building face each other, and users were mainly in the central part that is configured by the buildings. In the case of $O G C$, the concentration of users appeared to be near

(12) "affordances", be it material or nonmaterial, are those of its properties that enable it to be used in a particular way by a particular species or an individual member of that species, according to James J. Gibson (1979).

(13) In relation to the results and analysis of Hillier's study (1996, p. 194, italicized term by the authors): "the natural movement of moving strangers maintains natural surveillance on space, while the static inhabitants, through their dwelling entrances and windows, maintain natural surveillance of moving strangers. This formula clearly depends on the spatial configuration creating a strong probabilistic interface between inhabitants and strangers in space that is the source of safety." 


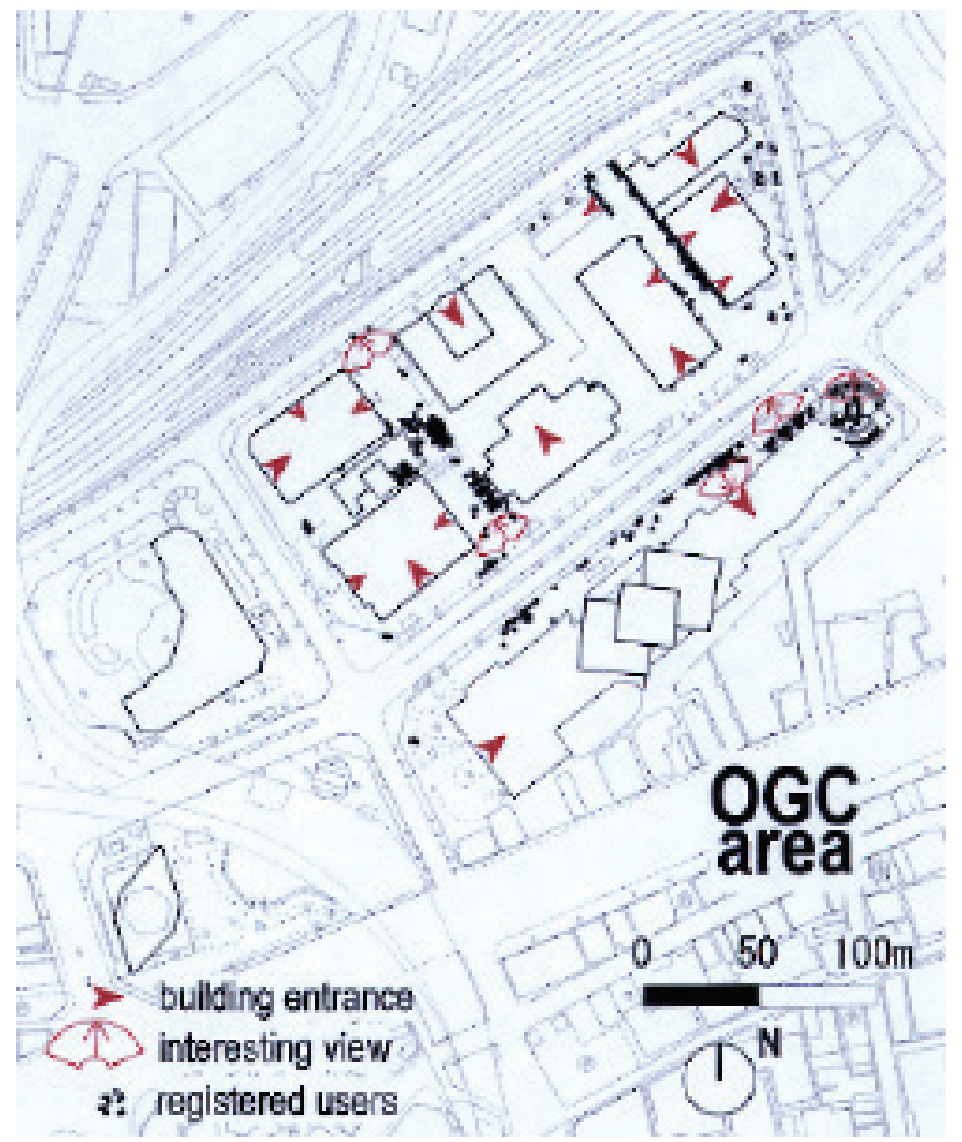

Figure 10.3: Mapping of users (overlay), views and entrances. OGC: Watching the urban scene

Source: Provided by the authors

\section{ATC}

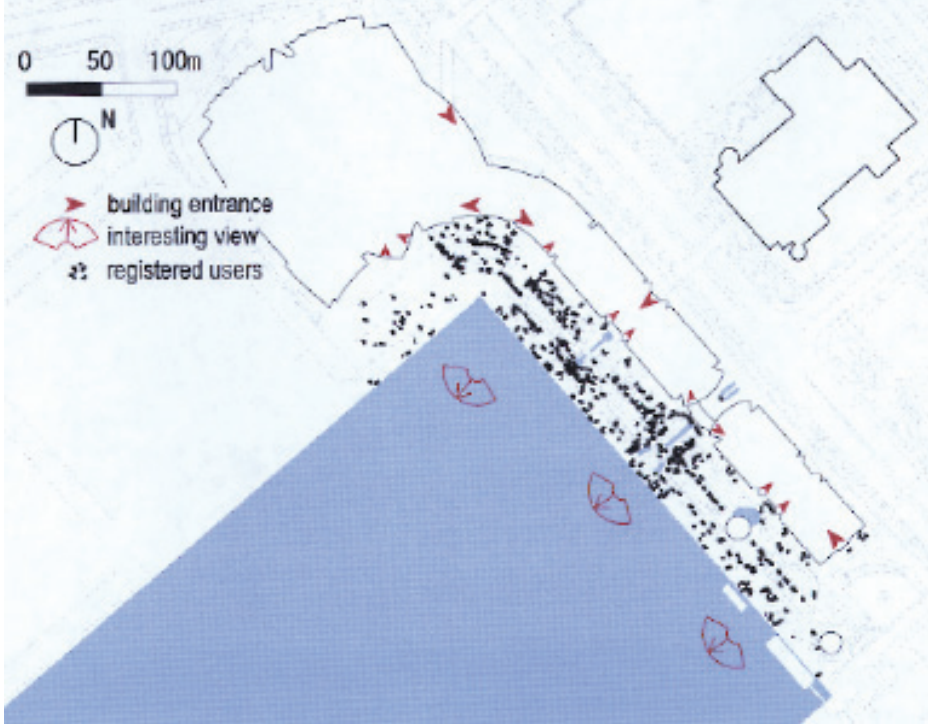

Figure 10.4: ATC:

The sea from the promenade and terraces

Source: Provided by the authors 
Figure 10.5: OBP:

Boulevard-like open spaces, turning users 'back on the rivers

Source: Provided by the authors

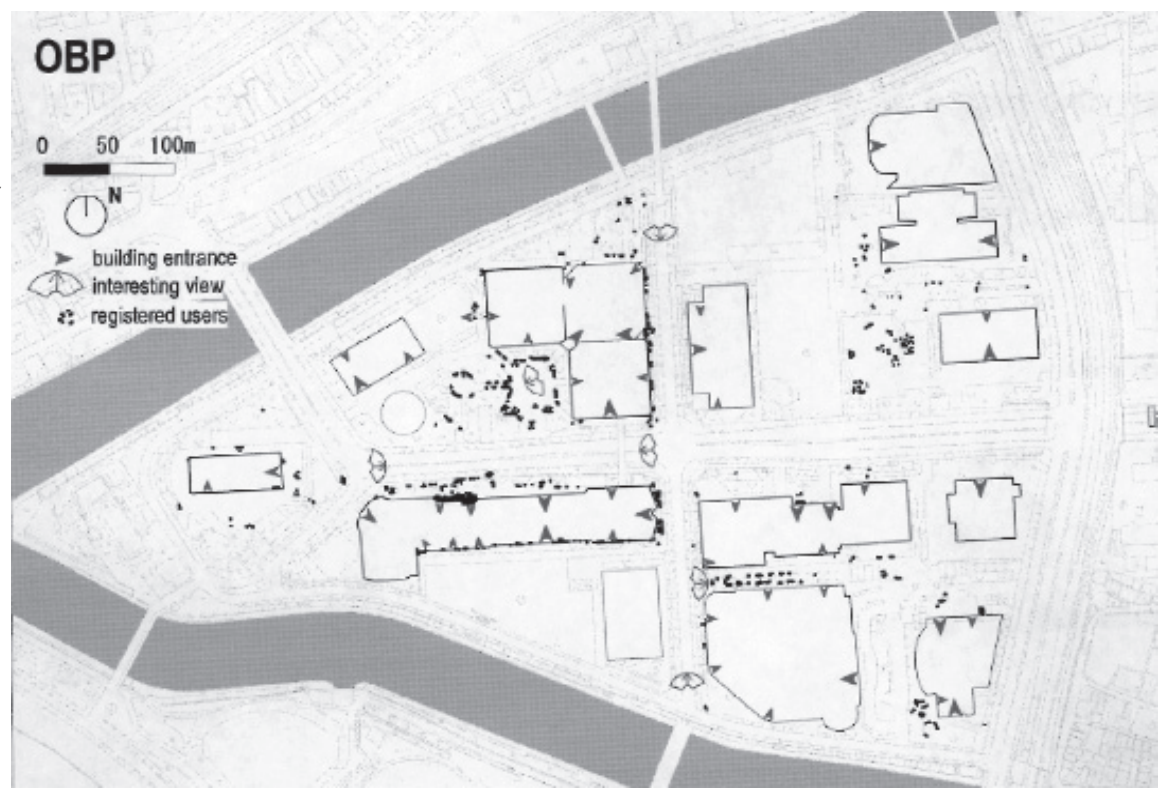

Photo 6. 1: Skyline of the city besides the Okawa river

Photo: Rogerio Akamine

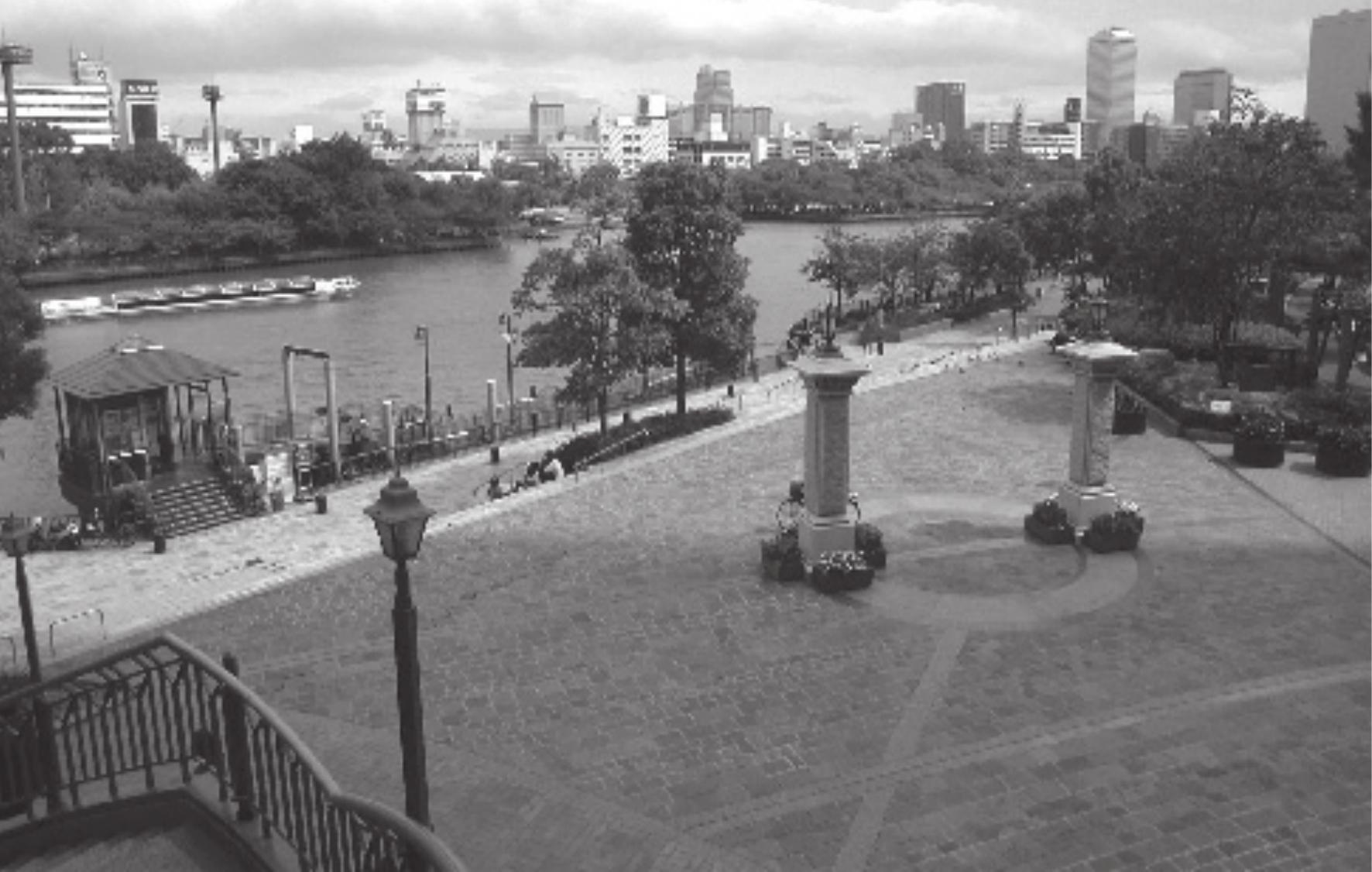




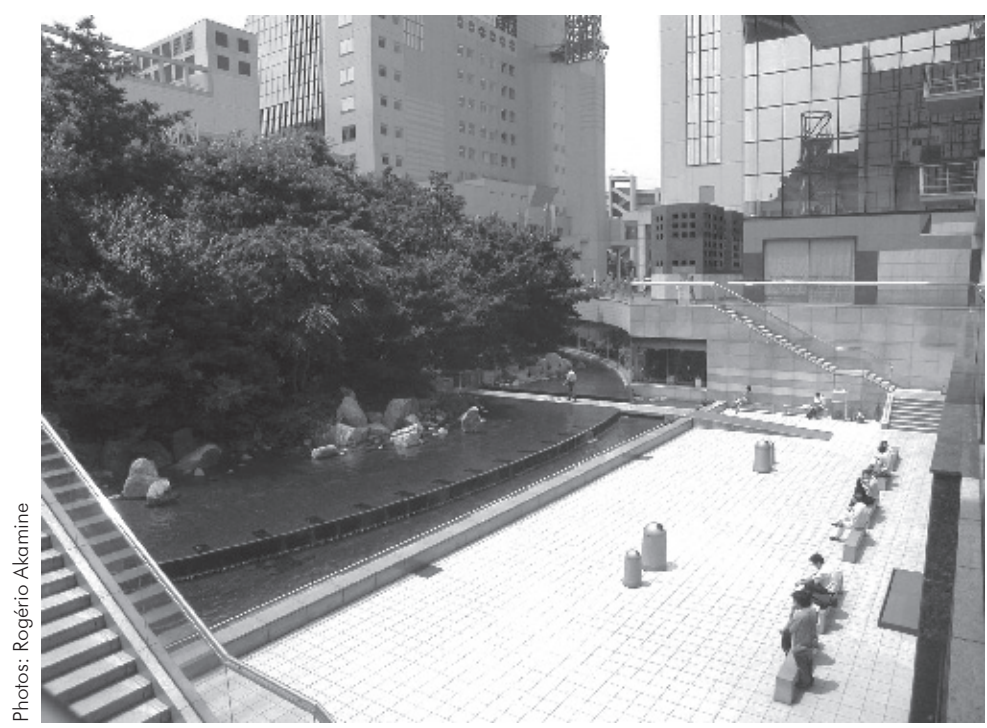

Photo 6.2: SUC - A

little wood in the city

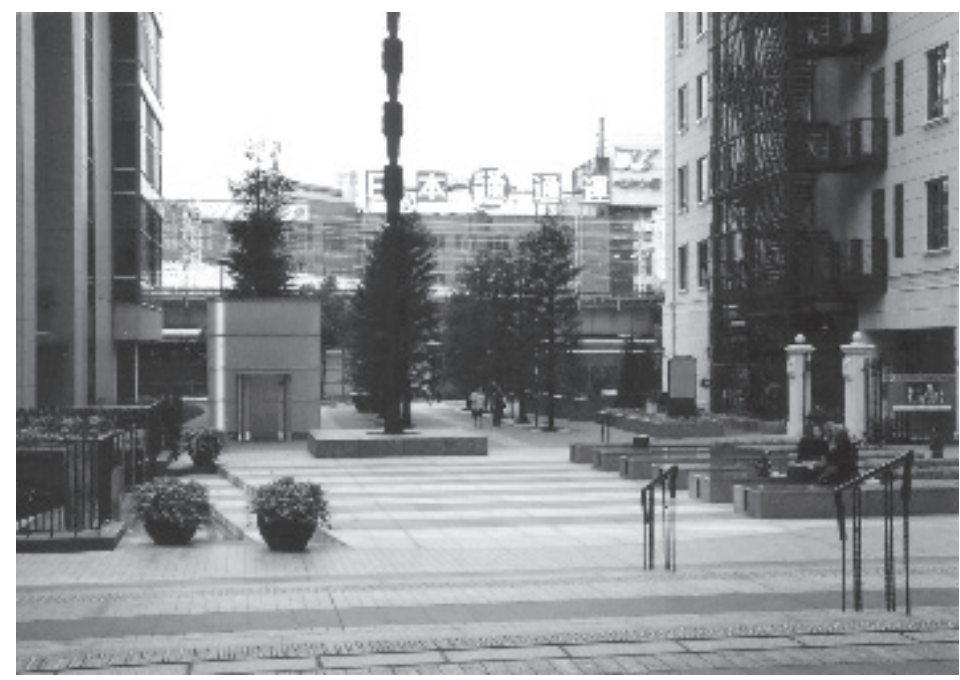

Photo 6.3: OGC

- At the back, rails

of trains, in the

scene, volumes to

sit, sculpture and trees

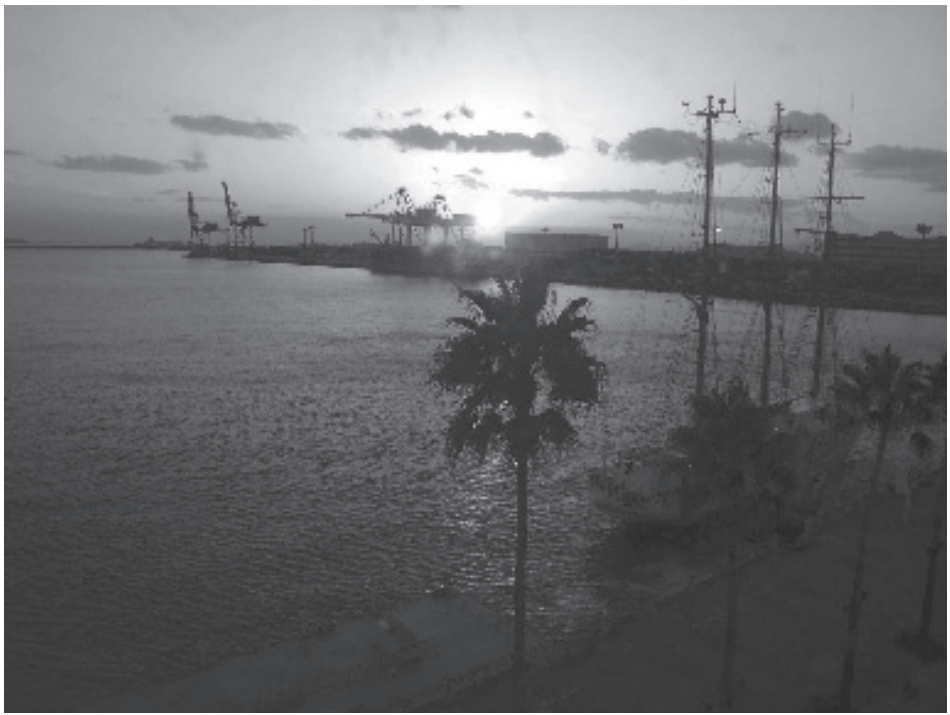

Photo 6.4: From

ATC, the sea and the sunset through the cranes 
Photo 6.5:

Boulevard in the

$\mathrm{OBP}$

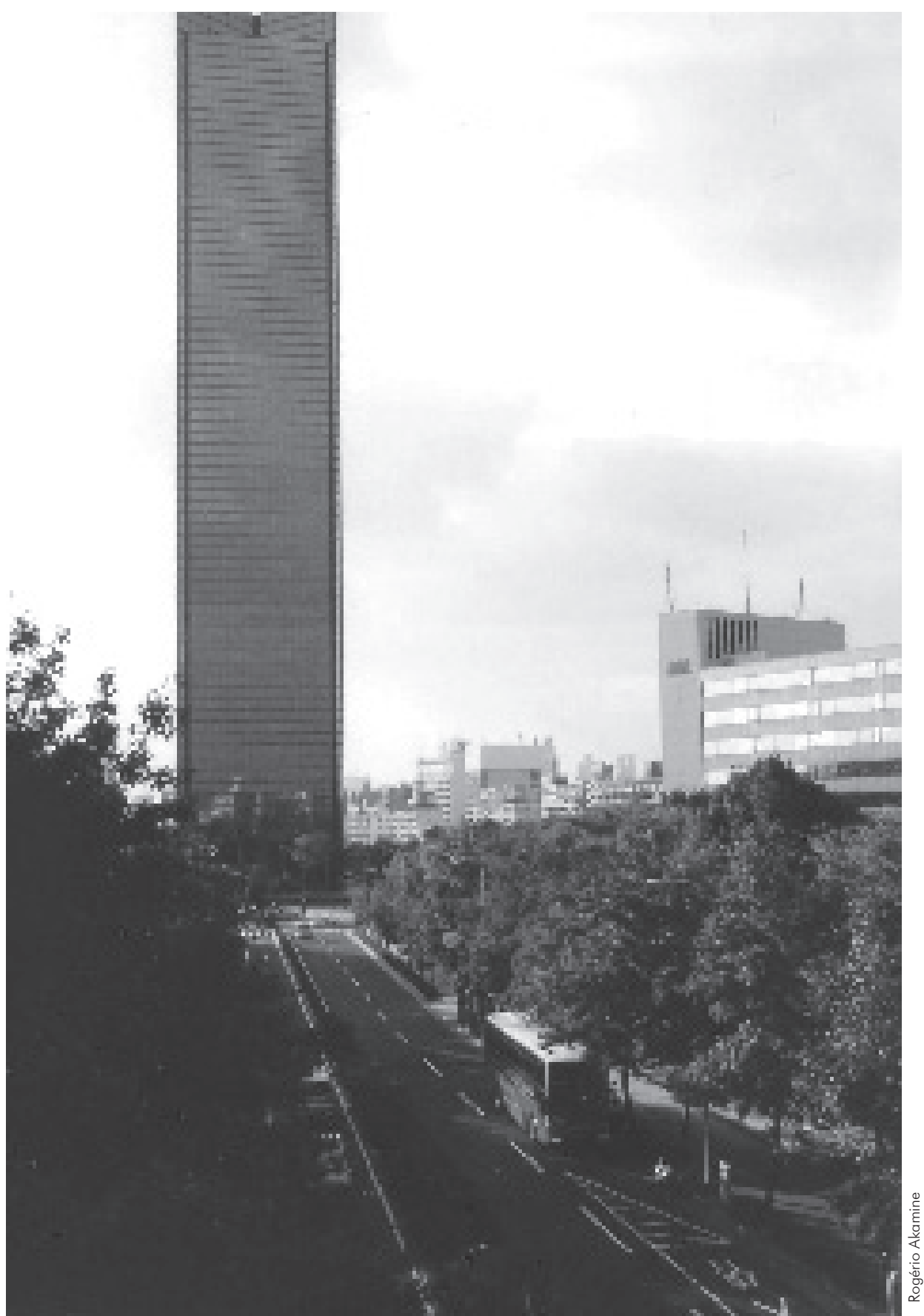

the café in the main open space. In the other side of street, the preferred places are clearly near the main entrances in the east extremity. The case of ATC is peculiar, as most accesses are easy in order to integrate the open space. At OBP, the place close to a fast food in the IMP building is visually marked. The linear distribution of users through north-south way in the center of the area is probably due to easy access to the Twin 21 and Matsushita IMP buildings. 
Even with sitting places and close to building entrances, other characteristic should be important to define preferred portions. Interesting views might be other factor to attract people to enjoy open spaces in pops. The preferred places are favorably disposed to attain best views, either natural or created (Figures 10.1 to 10.5 and Photos 6.1 to 6.5). In any case, the views are composed not only by natural elements, such as water, trees, flowered portions, rocks, but also by human activities, such as flow of passing people, movements of ships and cranes or traffic of trains and cars. Taking advantage of panoramic views in natural configurations should be obvious enough, but the case of OBP fails in this aspect. Unfortunately, the potential relation with two rivers and the landmark view of the historic Osaka castle were neglected. Just some boulevard-like spaces inside the site appear as configurations to views. An understanding of various kinds of experience in which views are concerned is useful to design conception. The sunken wood and flower fields of SUC are an example of creativity in arranging interesting scenes and environments.

Which beliefs and opinions users may have about open spaces in pops would complete information on design analysis.

\section{Conclusions}

The present study is an endeavour to deepen the understanding about use at open spaces resulted from public-private partnership. Because of the tendency toward urban renovations, which include the idea of privately owned public space, the results should be more and more evaluated to improve an effective public use. As a first approach to the theme, five significant urban projects in Osaka city were chosen to carry out systematic observation.

All the five cases are big projects, and most of the population aspects appeared differently. The counting of users during weekday and weekend day shows neither regularity in user density nor a similar variation in number.

The projects are evidently distinct from each other in features such as functions of buildings, space configurations, accesses and connections, views (natural or created) and sitting places. However, the common point among them is that such features are present in all cases, but arranged in different combinations. Other regularity is the occurrence of peaks during lunch time on weekday and late lunch time (about $15 \mathrm{Hs}$ ) on weekend day, when the amount of users reach a maximum value.

In relation to gender, there is balanced proportion of men to women. Nothing is possible to affirm about security of the place based on the proportions of women in pops at different hours of a day and days of the week.

Adults are the majority among the observed users, whereas the other groups were small in number. Then, the needs of children and older people at pops 
should be more investigated. Moreover, attractive conditions for disabled people should be also more available. Examples of improvements could be areas for children to ride bicycles and touchable water, more availability of comfortable benches in popular parts and gardens for people in wheel chairs. People of these groups or responsible for them should be heard.

How grouped the users were seen at the pops? The observation registers revealed that a large proportion was composed of two people and person alone. This information would serve as reference to define typology of furniture and dimensions of paths. On the contrary, the idea of versatile layouts could be arisen, because of the existent configuration may not afford bigger groups.

The intuitive image of business area of the analysed cases is reinforced by the registration of users according to the formality in dressing. The exception for big amounts of men in suits and women formally dressed were the students of a school of informatics. In other words, the types of activity in the buildings have direct relation to the profile of users that were observed. As the most affected by the relaxing of zoning rules are the neighbors, they should be consulted about the real possibilities and limitations for use of open spaces in the studied places.

According to the collected data, sitting and strolling represent the two most usual activities at pops. Sitting places, paths to walking and vigilance of guards keep the conditions for calm activities in contrast to the more active ones. Users were observed in relaxing activities including eating and talking more than playing balls or riding bicycles. When all cases are compared, not considering the areas, a wider variety of activity types leads to think in a superior quality in relation to those with limited number.

The most used parts in each studied place are revealed when behavioral mapping of different hours of the day are overlaid. Hence, places where users are commonly found may be related by proximity to the entrances of the existent buildings. There is an evidence for the relation: the nearer the entrances of buildings, the more used the parts of open space at pops. In the same way, interesting views either natural or created appear favorably to more frequent use of places than where there is nothing to attain. It would be also important to find the reasons why people don't use parts other than the preferred places.

After presentation of the main results from the study, it is possible to say that the investigation about the use of those open spaces at pops needs to go further. Here, all results form a first framework, an image of how open spaces at privately owned public space are being used. Then, asking opinions and beliefs of users by means of other techniques from the environment-behavior field 
would allow a more detailed understanding of a place, and in addition, create support to improve concepts of space design for public-private negotiations.

\section{References}

AKAMINE, Rogério. A study on use of large open spaces in privately owned public spaces from Osaka, Japan. 2003. 177 p. Tese (Doutorado). Osaka University Gradvate School of Engineering. Osaka, 2003.

ALTMAN, Irwin; ZUBE, Ervin H. (Eds.). Public places and spaces. New York: Plenum Press, 1989.

ALY, José Augusto Fernandes. Discussão acerca do papel urbano dos edifícios: Estudos e propostas para áreas em renovação. 2000. 171 p. Dissertação (Mestrado). Faculdade de Arquitetura e Urbanismo, Universidade de São Paulo, 2000.

GIBSON, James J. The ecological approach to visual perception. Boston: Houghton Mufflin, 1979.

HANAZATO, Toshihiro; TAKAHASHI, Takashi, ISHII, Kyoko et al. Description and analysis of people's distribution in the open spaces of housing estates. Journal of Architecture, Planning, and Environmental Engineering, AlJ. Tokyo: AlJ, n. 500, p. 87-93, 1997.

HILLIER, Bill. Space is the machine: A configurational theory of theory. Cambridge: University Press, 1996.

HIRAI, Sumio; NISHIMURA, Takashi. A study on the inhabitant's evaluation of the linear open space joining with river or road - from view-point of getting usefulness for daily life and residential area. Papers on City Planning, n. 36, p. 931-935, 2001.

HORIGUCHI, Sakiko; SUGITA, Sanae; DOHI, Masato. Sitting behavior on streets space from the aspects of spatial apparatus and sitting people's preference for sitting apparatus - A case study on Harajuku area Shibuya-ward Tokyo Pref. Papers on City Planning, n. 36, p. 763-768, 2001.

KURODA, Katsuhiko. Commercialization of waterfront development projects and cooperation between public and private sectors. In: INTERNATIONAL FORUM "WATERFRONT 2001". Osaka city: Waterfront 2001 organizing Committee, city of Osaka, p. 245-254, 2001.

LOUKAITOU-SIDERIS, Anastasia; BARNERJEE, Tribid. Urban design downtown; poetics and politics of form. Berkeley and Los Angeles: University of California Press, 1998.

MOORE, Gary T. Toward environment-behavior theories of the middle range. Advances in environment, behavior, and design. New York: Plenum Press, v. 4, p. 1-40, 1997.

134 NEWMAN, Oscar. Defensible space: Crime prevention through urban design. New York: Macmillan Publishing Co., Inc., 1973.

OSAKA CITY GOVERNMENT (JAPAN). Planning of Osaka city; city planning in Osaka city. Osaka: Congress Corporation, 1997. 
SOMMER, Barbara; SOMMER, Robert. A practical guide to behavioral research; tools and techniques. New York: Oxford University Press, 1997.

VEITCH, Russel (Ed.) Environmental psychology; an interdisciplinary perspective. New Tersey: Prentice Hall, 1995.

WATANABE, Tadashi; KATO, Koji; MIYAWAKI, Masaru; KITAHARA, Toshio. An experiment of the use of public space for activating the city center - A case study on "Citizens forum on urban design" in Chiba. Papers on City Planning. Tokyo: City Planning Institute, n. 36, p. 793-798, 2001.

WHYTE, Willian H. The social life of small urban spaces. Washington D.C.: The Conservation Foundation, 1979. 